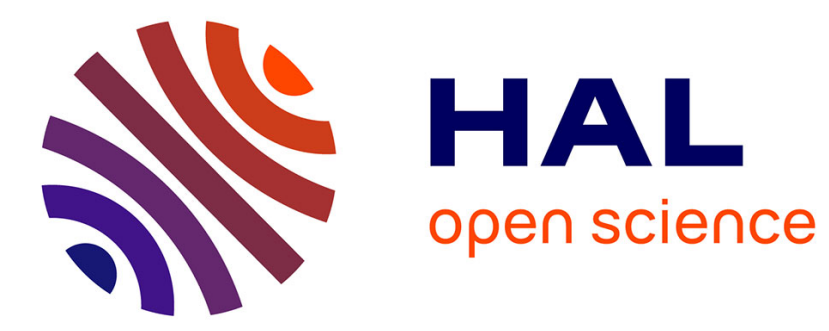

\title{
The Price Impact of Energy Vouchers
}

Marion Podesta, Jean-Christophe Poudou, Michel Roland

\section{To cite this version:}

Marion Podesta, Jean-Christophe Poudou, Michel Roland. The Price Impact of Energy Vouchers.

Energy Journal, 2021, 42 (3), pp.27-54. 10.5547/01956574.42.3.mpod . hal-02567375

\section{HAL Id: hal-02567375 \\ https://hal.umontpellier.fr/hal-02567375}

Submitted on 7 May 2020

HAL is a multi-disciplinary open access archive for the deposit and dissemination of scientific research documents, whether they are published or not. The documents may come from teaching and research institutions in France or abroad, or from public or private research centers.
L'archive ouverte pluridisciplinaire HAL, est destinée au dépôt et à la diffusion de documents scientifiques de niveau recherche, publiés ou non, émanant des établissements d'enseignement et de recherche français ou étrangers, des laboratoires publics ou privés. 


\title{
The Price Impact of Energy Vouchers*
}

\section{Marion PODESTA $\rfloor^{\dagger}$ Jean-Christophe POUDOU ${ }^{\ddagger}$ and Michel ROLAND $§$}

\author{
May 7, 2020
}

\begin{abstract}
France and South Korea have implemented voucher programs to counter energy poverty. In contrast to goods that traditional voucher programs target, the market structure that dominates energy supply is the oligopoly. In this paper, we study the price impact of vouchers in this market structure. We first state conditions on demand elasticities that make the choice of vouchers consistent with the regulator's objective of eliminating energy poverty. We then model a game between energy suppliers and the regulator, where suppliers maximize profit while the regulator ensures that no consumer spends more than a given share of income on energy. From a benchmark case without vouchers, we show that vouchers reduce the energy price under simultaneous decision making or when the regulator moves first. However, the price impact of vouchers is ambiguous if firms move first. This scenario's price is above the price of the simultaneous decision scenario's price.
\end{abstract}

JEL classification: D04; I38; L51; Q48

Keywords: Energy Poverty, Vouchers, Oligopoly, Regulation

*This paper was formerly titled "Public Policies against Energy Poverty in Deregulated Markets" when presented in conferences. The authors acknowledge the support of the French Agence Nationale de la Recherche under grant ANR-14-CE05-0008 (project "Sustainably REducing energy poVErty"). We thank participants at the JMA 2018 in Bordeaux, at the EARIE Conference 2018 in Athens, at the XII JEI in Barcelona, at the $2^{\text {nd }}$ ICEFM in Montpellier and at the $24^{\text {th }}$ EAERE Conference 2019 in Manchester, as well as Stefan Ambec, for their comments. We also thank participants at seminars in Annecy, Antwerp and Perpignan.

${ }^{\dagger}$ Corresponding author: ART-Dev, University of Perpignan, Chemin de la Passeo Vella, BP 79905, 66962 Perpignan Cedex 9. marion. podesta@univ-perp.fr

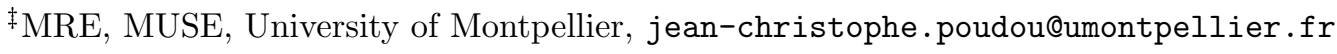

${ }^{\S}$ CREATE, Université Laval, Michel. Roland@ecn.ulaval.ca 


\section{Introduction}

France and South Korea have recently implemented vouchers that allow consumers to pay for energy services such as electricity and gas. The objective of this program is to counter "energy poverty", which occurs when "a household is unable to afford the most basic amount of energy for adequate heating, cooking, lighting, and use of appliances in the home." (Charlier and Legendre [9]). Both countries measure energy poverty by the criterion proposed by Boardman [7] in her seminal contribution on the subject: ${ }^{1}$ households who spend more than $10 \%$ of their income on energy housing services (ADEME [1] and MOTIE [34]). By this criterion, the problem seems far-reaching: the Environment and Energy Management Agency of France estimates that 3.8 million French households - or $14 \%$ of households - were energy poor in 2018 (ADEME [1]). According to the Ministry of Trade, Industry and Energy of South Korea, the corresponding number for this country is 1.78 million households, or $11.6 \%$ of households in 2011 (MOTIE [34]). The voucher programs are thus of a large scale: the French Ministry for the Ecological and Inclusive Transition mentions that 3.6 million households $^{2}$ received them in 2018 for an average amount of $€ 150$ per household and per year (MEIT [32], [33]). Even though, to our knowledge, there is no governmental source that supplies such statistics in South Korea, by coupling data from Yun and Park [48] and Yoo and Seo [47], we can estimate that 1.57 million Korean households were eligible for vouchers in 2015, for an average of approximately 101,000 won (W). ${ }^{3}$ Programs of such scale are likely to have a significant impact on market demand.

Although the use of vouchers to subsidize necessary goods has existed for a long time, they traditionally target goods supplied by private firms with relatively low market power at the national level (e.g. food and housing) or by non-profit organizations (e.g. education and health care). ${ }^{4}$ In contrast, the market structure that dominates energy supply is one of

\footnotetext{
${ }^{1}$ Boardman initially used the term "fuel poverty", but this term has come to be considered narrow and is now being replaced by the term "energy poverty" (MacKerron [30]). For our purposes, "energy poverty" is more appropriate because the voucher programs considered allow the purchase of electricity and gas and because it corresponds to the translation of "précarité énergétique", which is the term used in the French regulation.

${ }^{2}$ The website mentions that this number should increase by 2.2 million in 2019 .

${ }^{3}$ The average exchange rates for 2018 were $€ 1.18 /$ US\$ and $W 0.00091 /$ US $\$$ (Bank of Canada [5]).

${ }^{4}$ In the case of education, the purpose of vouchers is to increase, through increased competition, the quality rather than the quantity of service
} 
a national oligopolistic network industry. ${ }^{5}$ Firms of such an industry can have a strategic response to any policy that impacts it.

This paper studies the impact of voucher distribution on the final price of the targeted good (hereafter, energy) in the context of an oligopolistic industry. Its main contribution is to the literature on vouchers and it is threefold. First, we take into account the strategic reaction of firms on the supply side of the market, while the rare theoretical papers that study the impact of vouchers on the equilibrium price, such as Bradford and Shaviro [8], consider a passive supply side with the usual upward sloping supply curve. Second, we endogenize the value of vouchers that the regulator emits instead of considering that vouchers are an exogenous shift of the demand curve. Third, we state demand conditions under which vouchers are potentially an adequate redistributive instrument in an oligopolistic market.

We also contribute to the literature on energy poverty because, while this literature has focused mainly on the measurement of energy poverty, we focus on the impact of an actual program aimed to fight it. As mentioned by Chaton and Lacroix [10], "[t]he lack of consensus on a definition obviously makes it difficult to determine how to measure fuel poverty". Thomson et al. [45] classify proposed measurement methods in three approaches: the expenditure, the consensual and the direct approaches. ${ }^{6}$ The Boardman definition used by the French program belongs to the first approach. However, within this approach, there are also debates on the way to measure expenditure, the proper concept of income to be used as well as the expenditure-to-income ratio to use (Moore [36]). ${ }^{7}$ Our model is general enough to make our results independent of the exact way energy expenditure or income are defined or measured within the expenditure approach. ${ }^{8}$ We thus extract ourselves from the measurement debates on energy poverty to rather determine the foreseeable market consequences of an actual policy implemented to fight it.

More precisely, we aim to determine whether a voucher program has a price impact over and above its redistributive impact. Other policy measures have been proposed to fight energy poverty. For instance, a regulatory approach is to impose increasing block pricing,

\footnotetext{
${ }^{5}$ Measures of industry concentration for the specific cases of France and South Korea are given in Section 2 .

${ }^{6}$ We describe these approaches in Section 6.

${ }^{7}$ Some of the measures even dispense with the income measure such as the "fuel poverty ratio with a dynamic threshold based on twice median spending", one of the six energy poverty measurements that Hills [22] proposes.

${ }^{8}$ In section 6 , we discuss extensions that would allow us to evaluate the price effect when energy poverty is measured along the two other approaches.
} 
so that basic consumption is cheaper than less necessary consumption. A comparative advantage of the voucher program is its relative simplicity and the fact that it separates the distribution policy from the realm and the complexities of the industry regulation. Accordingly, Léautier ([27], p. 130) considers vouchers to be "much less disruptive, hence preferred by economists". However, to our knowledge, the impact of this redistribution policy on price has not been analyzed, so that this preference is not necessarily warranted. In particular, the prospect that vouchers could bring a price increase and, consequently, could themselves have a perverse detrimental effect on energy poverty has not been considered and analyzed.

In our modelization of voucher programs, we adopt a positive approach. The main reason is that economic justifications of vouchers are not a settled issue in terms of the regulator's objective that underlie them and of their efficacy to meet this objective relative to cash transfers. For instance, Bradford and Shaviro [8] invoke paternalism, externalities and distribution as potential motivations to implement vouchers. We remain agnostic about these motivations and rather observe that vouchers have been implemented for a long time for various commodities, such as food and education, and that there is a recent trend to extend them to new commodities, such as energy. In our case, we take as given the policy of eliminating energy poverty and we model it as a constraint to the regulator. We analyze the price impact of this policy under the assumption that it is pursued at minimum cost. ${ }^{9}$

In this approach, we first state conditions on individual and aggregate energy demand elasticities that make the choice of vouchers consistent with the elimination of energy poverty. We then model a game between the energy suppliers and the regulator, where firms maximize profit under Cournot competition, while the regulator emits vouchers in quantities that ensure that no consumer spends more than a given share of her income on the targeted good. From a benchmark case with no vouchers, we analyze the impact of their introduction in three settings: one where firms and the regulator make decisions simultaneously, one where firms move first and one where the regulator moves first. The first setting corresponds to a case where neither the industry nor the regulator has a commitment power that enables it to announce its decision first and stick to it. The two others correspond to cases where this commitment power exists for the firms or for the regulator.

We impose two conditions on individual energy demand elasticities. First, the individual income elasticity is less than one, i.e. energy is a necessary good. Second, the individual

\footnotetext{
${ }^{9}$ Accordingly, ex ante energy poor consumers are necessarily beneficiaries of programs. Depending on the price impact, other consumers will see their surplus increase or decrease, while the surplus of ex ante energy poor consumers will be greater or lower than that expected without taking this impact into account.
} 
price elasticity increases with income. ${ }^{10}$ Since a prime cause of energy poverty is high energy prices, ${ }^{11}$ the absence of any one of these conditions would make vouchers an inadequate instrument to ensure that low-income consumers do not spend more than $10 \%$ of their income on energy. On the one hand, if energy were a luxury good, it is the richest consumers who would be at risk of exceeding this 10\% threshold. On the other hand, if the poorest consumers had an elastic demand, a "solution" to energy poverty would be to favor an energy price increase, as it would bring a reduction in the expenditure of energy. This would contradict the perception that high prices, due to either a lack of competition and/or environmental policies, are the sources of the problem.

On the supply side, we analyze the impact of vouchers on the "overall" market power of the industry, as defined by the difference between the final price paid by the consumer and the marginal cost of producing, transporting and delivering energy to this consumer. ${ }^{12} \mathrm{We}$ thus abstract from the many complexities of the energy industry markets and of the national regulatory frameworks, including regulations on vertical integration or separation. In practice, market power can be exercised in many different ways at any stage of production, ${ }^{13}$ and the exact source of the price markup is immaterial to us. To avoid the intricate difficulties of measuring concentration in the energy industry ${ }^{14}$ and to relate the analysis to the simplest industrial organization model possible, we use a Cournot model and represent the industry structure by the number of firms.

Under these conditions, we show that the implementation of the voucher program reduces the energy price under simultaneous decision making or when the regulator moves first. However, the impact of vouchers on the energy price is ambiguous if firms move first. This scenario's price is above the price of the simultaneous decision scenario's price. The

\footnotetext{
${ }^{10}$ We also make a sufficient condition on aggregate demand to ensure the existence and uniqueness of the market equilibrium.

${ }^{11}$ The French observatory of energy poverty (ONPE [37]) sees energy poverty as the combination of four factors: the price of energy, household income, poor housing conditions or heating equipment, and household habits.

${ }^{12}$ This approach allows us to conform to the formal definition of market power, which is: "[t]he ability to alter profitably prices away from competitive levels" (Mas-Collel [31], p. 383).

${ }^{13}$ In addition to concentration at the generation and retail stages, market power can depend on transmission constraints, the absence of forward markets, horizontal differentiation of retailers, a lack of information among final consumers, etc. Léautier [27] gives comprehensive treatments of market power at each stage of production.

${ }^{14}$ See Stoft [44] for an account of these difficulties.
} 
possibility of a price reduction can be surprising at first since diverting the consumption towards energy to a certain extent would seem to increase the market power of energy suppliers. This does not occur because the distribution of vouchers increases the price elasticity of demand of eligible consumers, so that it in fact decreases the market power of suppliers. This reduction of market power can, however, be partially or fully countered by firms when they move first.

A surprising policy implication of the paper is that vouchers have the potential to partially reinstate price control over a deregulated energy industry in particular or over any oligopolistic industry in general. The literature on public policy suggests the possibility of a causal link between energy market restructuring and energy poverty. For instance, Haber [21], Majone [29] and Finger and Finon [18] argue that market efficiency is the primary goal of restructuring and that the core mandate of regulatory agencies is to eradicate market failures rather than pursue social justice or equity. Empirically, Poggi and Florio [39] provide evidence that privatization and vertical disintegration in Europe has increased the probability that consumers experience energy poverty. They also comment that the opening of markets in electricity and gas in the European countries have "not yet been effective enough in containing the effects of the [privatization and disintegration] reforms on the most vulnerable users." 15 Similarly, Chester and Morris [11] contend that "[t]he numbers judged energy-poor are most prevalent in countries with restructured electricity sectors". Florio [19] concludes that "[o]ne clear policy implication of our research is that in energy industries, consumers still need a specific regulatory environment to protect them...This protective regulatory attitude would particularly be important to address concerns for energy poverty." Another source of the price increase behind energy poverty can be the cost of environmental policy. For instance, Poser et al. [40] mention that "[r]etail electricity prices have increased in Germany due in part to the generous subsidies for renewable energy" and Léautier ([27], p. 287) that "in 2016, a German retail customer paid $€ 30 / \mathrm{MWh}$ for the wholesale cost of energy and around $€ 60 /$ MWh for the RES [renewable energy source] subsidy". Neuhoff et al. [38] also observe that "[s]ince 2008...electricity prices have increased in real terms by twelve percent because of the rising EEG [Renewable Energy Sources Act] charges" and that poor households are unsurprisingly the most affected: "while 0.9 percent of the consumer spending of the ten percent of households with the lowest income will be for the EEG surcharge in 2013, this figure is just 0.4 percent for the highest income decile". Whatever the

\footnotetext{
${ }^{15}$ The most recent year of sample data is 2005 .
} 
reason that is at the source of energy poverty, ${ }^{16}$ we show that it is possible to use vouchers as a substitute for price regulation if given demand conditions are satisfied in spite of the energy suppliers market power,

The next section briefly describes the energy voucher programs as well as the electricity and gas industry structures in France and South Korea. In Section 3, we develop the benchmark model with the consumers' and firms' behaviors, including the conditions on demand elasticities, prior to the introduction of vouchers. Section 4 analyzes the impact of the presence of vouchers on these behaviors and presents the regulator's policy. In Section 5 , we model a game between the regulator and the industry and analyze three cases: $(i)$ the regulator and the industry's firms make simultaneous decisions, $(i i)$ the regulator moves first, and (iii) the firms move first. Section 6 discusses the robustness of the results to a change in the definition of energy poverty. We conclude with the lessons that the model brings and with some extensions that can be envisioned.

\section{Energy Voucher Programs in France and S. Korea}

\section{$2.1 \quad$ France}

The energy voucher scheme has been implemented in France since 2018, after two years of experimentation in four French departments. In 2016 and 2017, approximately 17,000 energy vouchers were distributed in the four departments. Eligibility is defined along two parameters: the household reference tax revenue (RTR) and the number of units of consumption (UC). The latter is a weighted measure of the household size: the first person of the household corresponds to $1 \mathrm{UC}$, the second to $0.5 \mathrm{UC}$, and each additional person to 0.3 UC. In 2018, households with income less than or equal to $€ 7,700$ per year and per UC were eligible. ${ }^{17}$ This threshold was increased to $€ 10,700$ in 2019 . For eligible consumers, the face value of vouchers (all taxes included) depends on the RTR per unit of UC as described in the following table.

\footnotetext{
${ }^{16}$ Factors outside the energy industry have also contributed to energy poverty. For instance, Miniaci et al. [35] mention that, in general, energy affordability "problems are likely to have been exacerbated by the recent financial crisis" and confirm this has been the case for Italy in particular.

${ }^{17}$ For instance, couples with two children are eligible if their income is below $€ 16,170$.
} 


\begin{tabular}{|l||c|c|c|c|c|c|c|c|}
\hline \multicolumn{1}{|c||}{} & \multicolumn{7}{c||}{ Level of RFR/UC (€) } \\
\hline \hline & $0-5,600$ & $5,600-6,700$ & $6,700-7,700$ & \multicolumn{2}{|c|}{$7,700-10,700$} \\
\hline \hline & 2018 & 2019 & 2018 & 2019 & 2018 & 2019 & 2018 & 2019 \\
\hline $1 \mathrm{UC}$ & 144 & 194 & 96 & 146 & 48 & 98 & - & 48 \\
\hline $1<\mathrm{UC}<2$ & 190 & 240 & 126 & 176 & 63 & 113 & - & 63 \\
\hline $2 \mathrm{UC}$ or + & 227 & 277 & 152 & 202 & 76 & 126 & - & 76 \\
\hline
\end{tabular}

Table 1: Voucher Allocation

The following energy expenses can be paid with an energy voucher: electricity, natural gas, heat, liquified petroleum gas (LPG), heating oil, wood, biomass, or other fuels intended for heating or hot water production. Energy vouchers can also be used for energy efficiency renovations.

The evaluation report of the 2016-2017 by the French Ministry for the Ecological and Inclusive Transition (MEIT [32]) mentions that the distribution of beneficial households in 2017 was the following :

\begin{tabular}{|l||c|c|c|}
\hline \multicolumn{1}{|c||}{} & \multicolumn{3}{c|}{ Level of RFR/UC (€) } \\
\hline \hline & $0-5,600$ & $5,600-6,700$ & $6,700-7,700$ \\
\hline \hline $1 \mathrm{UC}$ & $31 \%$ & $6 \%$ & $7 \%$ \\
\hline $1<\mathrm{UC}<2$ & $23 \%$ & $5 \%$ & $5 \%$ \\
\hline $2 \mathrm{UC}$ or + & $15 \%$ & $4 \%$ & $4 \%$ \\
\hline
\end{tabular}

Table 2: Distribution of Beneficiaries

The average amount of energy vouchers is $€ 150$. Almost $70 \%$ of the beneficiaries are in the lowest income range. For these poor households, the average amount of energy vouchers is approximately $€ 170$. In 2019 , an increase in the face value of the energy vouchers will make the average amount reach $€ 200$ per household and per year.

During the experiment, 9 of 10 vouchers were used to pay an electricity or gas bill: $61.5 \%$ for electricity and $29 \%$ for natural gas. Only $6.4 \%$ of vouchers were used to pay heating fuel, and $2.6 \%$ to pay wood, domestic LPG, or other fuels. A residual $0.05 \%$ was used for efficiency 
renovations (MEIT [32]). In brief, the bulk of voucher expenditures were made on electricity and gas.

It turns out that electricity and gas are concentrated industries. The French regulator for the energy sector, the Commission de régulation de l'électricité (CRE [14], [15]), reports a quarterly HHI for electricity generation that varies between 4,201 (Q2) to 7,362 (Q3) in 2018 as well as HHIs over 4,000 for the electricity and natural gas retail sectors at the end of the second quarter 2019. ${ }^{18}$

There are regulated end-user prices for both electricity and gas that are offered by incumbent suppliers. Non-regulated end-user prices can be proposed by entrants and by incumbents. Although the proportion of consumers under the regulated tariffs is still very important, there are recent signals that it is decreasing: CEER [13] reports that $86 \%$ of electricity household consumers and $53 \%$ of gas household consumers were under regulated prices in 2016, while these numbers decreased to $82 \%$ and 46\%, respectively, in 2017.

\subsection{South Korea}

In January 2014, the South Korean government announced the introduction of an energy voucher program in its $2^{\text {nd }}$ National Energy Master Plan (MOTIE [34]). This voucher program concerns various types of energy, including electricity, gas and kerosene, to ease the energy burden on low-income families during the winter season. Eligibility includes all "Basic Livelihood Program" beneficiaries as well as the disabled, elderly and families with young children in the second lowest income bracket. ${ }^{19}$ The amount allocated depends on the size of the household: $\$ 84,000$ for single-person household, $\$ 108,000$ for a two-person household and $\$ 121,000$ for households with three or more persons. (Yoo and Seo [47]). Coupling these data with those found in Yun and Park [48] allows us to estimate the average voucher value at $\$ 101,000$.

\footnotetext{
${ }^{18}$ These are the last data available. The CRE considers that a HHI between 2,500 and 10,000 indicates a high market concentration (CRE [14], p. 11). Note that all gas in France is imported, so that there is no production sector.

${ }^{19}$ The Basic Livelihood Program is the general social security program for the poor. It is offered to households whose main earners' income is below a given percentage of the standard expenses for basic livelihood (130\% in 2011 according to Jeon and Chung [24]). A family in the second lowest income bracket is "a family whose income is under $120 \%$ of the minimum cost of living" (MOTIE [34]).
} 
Yun and Park [48] also provide separate proportions of eligible households by income decile and by household size, as presented in the following tables for the 2006-2015 period. ${ }^{20}$

\begin{tabular}{|c||c|c|c|c|c|}
\hline Income Decile & 1 & 2 & 3 & 4 & 5 to 10 \\
\hline$\%$ & 60.2 & 22.7 & 3.4 & 0.3 & 0.0 \\
\hline
\end{tabular}

Table 3: Proportion of Eligible Consumers by Income Decile

\begin{tabular}{|c||c|c|c|c|c|}
\hline Household Members & 1 & 2 & 3 & 4 & 5 and more \\
\hline$\%$ & 19.6 & 13.9 & 3.5 & 1.9 & 4.1 \\
\hline
\end{tabular}

\section{Table 4: Proportion of Eligible Consumers by Household Size}

These data suggest patterns that are similar to those of the French case. In both cases, the lowest-income households are the main beneficiaries of vouchers.

Wherever access to natural gas is ensured, the use of vouchers in South Korea is likely to be similar to the one observed in France: ${ }^{21}$ in urban areas, the share of energy expenditures spent on electricity was $47.6 \%$ and the share spent on gas, which has a penetration rate of $90.5 \%$, was $41.6 \%$. However, because of a gas penetration rate of only $52.9 \%$ in rural regions, the share of energy expenditures on gas is only $19.9 \%$. Since electricity has a national penetration, it gets a 50.6\% energy spending share. Other energy sources, mainly kerosene and LPG, take up the remaining 29.5\%. As the absence of natural gas increases total energy expenditure, Yoo and Seo [47] recommend that "the current voucher program adds a residential district as a criterion of support".

For the moment, the electricity sector remains monopolistic. A staged restructuring plan designed to promote market-oriented reforms from "generation to wholesale and on to retail" (Kwon and Kim [26]) has never been fully carried out because of political oppositions at the various stages. The formerly vertically integrated Korea Electric Power Corporation (KEPCO) saw its generation assets divided into five fossil-fuel generation companies and one nuclear generation company. The Korea Power Exchange (KPX) was established for an independent system and market operation. However, generation companies are still owned by

\footnotetext{
${ }^{20}$ Because data on the number of households in each decile are not presented, we cannot couple the data of these tables to present the percentage of households by per capita income.

${ }^{21}$ The following data come from Yoo and Seo [47].
} 
KEPCO and there is still no competition in wholesale and retail markets. The governement's stake in KEPCO is now 18.2\% (KEPCO [25]). Overall, Kwon and Kim [26] come to the conclusion that "[a]s in many other countries, we end up with a hybrid form of privatization in which an industry is neither wholly privatized nor dominated by a state organization that can do as it pleases" and they expect "more incremental steps toward greater privatization in electricity generation and distribution".

The natural gas sector is also highly concentrated. According to IEA [23], in 2011, the Korea Gas Corporation (KOGAS) was responsible for $95 \%$ of Korea's total gas imports, in the form of liquified natural gas (LNG). It owns and operates four of the six LNG import terminals. The other two are owned and operated by two different private companies, whose presence is meant to "generate competition in the gas market and reduce other price distortions that were seen to be increasing costs in the supply chain" (ANRC [2]). KOGAS is also responsible for the gas transmission pipelines, whose expansion is planned by the government. Where available, a "City Gas Company" retails gas to final consumers through their own distribution pipeline (IEA [23]).

Tariffs for both electricity and gas distribution are regulated. ${ }^{22}$ Accordingly, although it recognizes that South Korea maintained a commitment to the electricity sector reform, the 2012 IEA report (IEA [23]) on South Korea energy policy recommended to further it and to accompany it with a reform of the gas sector.

\subsection{Key Common Features}

From the preceding descriptions, we can now identify the key common features of these two experiences that we wish to capture in our model in order to characterize the price impact of vouchers.

First, both countries adopt the share of energy expenditure in income as a measure of energy poverty. ${ }^{23}$ To foresee the impact of the programs, our model thus uses this measure. However, as it has been criticized on several counts in the literature, we discuss in Section 6

\footnotetext{
${ }^{22}$ See Yi and Park [46] for electricity and ANRC [2] for gas.

${ }^{23}$ They also set a maximum eligible income to avoid that wealthy consumers become beneficiaries of the programs because they choose to spend a high share of income on complementary luxury goods (e.g. heated pool). This would be a case of "overconsumption" (see Miniaci et al. [35]). The assumptions of our model de facto eliminate such cases, but section 6 discusses how to take them into account in a more general setting.
} 
how our model can be amended to evaluate voucher programs that would use other energy poverty measures.

Second, the gas and electricity retail markets are highly concentrated. As a result, we represent the energy sector in our model as an oligopolistic industry. To make the model as simple as possible and to derive intuitions with models similar to those found in the industrial economics literature, we assume that market power is measured by the number of firms $n$. As firms in the electricity and gas sectors can be of very different sizes, this number can be taken in practice as the reciprocal of the HHI index to take into account differences in market shares. Then $n$ represents the number of firms of equal size that is equivalent to the HHI.

Our aim is to analyze the use of vouchers in an otherwise deregulated market to single out an eventual distortionary price impact of vouchers. As a result, even though energy sector regulation in general and retail price regulation in particular are still important in both countries, we assume that actors in the energy industry are private profit-maximizing firms. ${ }^{24}$

\section{Benchmark Model}

In this section, we model the energy market characteristics before the introduction of vouchers. We put together assumptions that make a priori plausible a regulator's choice of the voucher instrument as a way to limit the consumer energy expenditure share. More precisely, through these assumptions, we eliminate market conditions in which using vouchers would be inappropriate because they will tend to increase the energy expenditure share rather than decreasing it.

\subsection{Consumer Behavior and Individual Demands}

We consider heterogeneous consumers that have the same preferences for energy and a composite numeraire good but have different income levels. These preferences are represented

\footnotetext{
${ }^{24}$ Note also that we want to evaluate distortionary pricing under the assumption (or the constraint) that the voucher program objective is met. In other words, energy poverty, as defined by the policy, is necessarily eliminated by the program. By construction, the model is thus not meant to evaluate the performance of the program in terms of energy poverty. Rather, it aims to look at the market consequence of this program.
} 
by the utility function $U(q, y)$, where $q$ is the consumption of energy and $y$ is the numeraire. $U$ is differentiable, strictly increasing and strictly quasi-concave. We let $\theta$ denote a consumer's income level. The population's income is continuously distributed according to the differentiable function $F(\theta)$ over the set $\Theta=[\underline{\theta}, \bar{\theta}]$.

Without vouchers, the consumer's problem is regular and, from it, we obtain individual demand functions $\hat{q}(p, \theta)$ and $\hat{y}(p, \theta)$ that follow usual properties, where $p$ is the final price to the consumer. However, we further characterize the demand of energy to represent particular properties that seem consistent with a regulator's willingness to cap the energy spending share. Denoting the income elasticity of demand by $\varepsilon(p, \theta) \equiv \hat{q}_{\theta}^{\prime} \frac{\theta}{q}$, the price elasticity of demand by $\eta(p, \theta) \equiv-\hat{q}_{p}^{\prime} \frac{p}{q}$ and the elasticity of the demand slope by $\omega(p, \theta) \equiv \frac{\hat{q}_{p}^{\prime \prime}}{\hat{q}_{p}^{\prime}} p$, we make the following set of assumptions on the individual energy demand.

Assumption 1 For all $(p, \theta)$,

a) $\varepsilon(p, \theta)<1$

b) $\eta_{\theta}^{\prime}(p, \theta)>0$ and there exists an income level $\hat{\theta}(p) \geq \underline{\theta}$ such that $\eta(p, \hat{\theta}(p))<1$

c) $\omega(p, \theta) \geq-2$

The assumption that energy is a necessary good implies that the energy expenditure share decreases with income so that the relative burden of energy spending is the higher the lower the consumer's income. ${ }^{25}$ It is the basic justification behind a means-tested policy such as vouchers. The assumption that the price elasticity of energy increases with income and that there exist consumers with inelastic demand among the poorest consumers means that the energy spending of a class of the poorest consumers increases with increases in price. $^{26}$ This assumption is consistent with the stylized fact that energy prices have increased

\footnotetext{
${ }^{25}$ Bakaloglou and Charlier ([4], p. 21) survey 18 studies on the income elasticity of energy in various countries and the results span from 0.02 to 0.15 . The results of the two studies about France are at the low end of this interval: 0.0294 to 0.0443 .

${ }^{26}$ For France, Bakaloglou and Charlier ([4], p. 24) obtain that "the magnitude of the [energy] price elasticity differs between low and high levels of revenue. It is lower for low-income households $(-0.43)$ and higher for high-income households $(-0.714)$, meaning that poor households are less responsive to an increase in energy prices". In contrast, Reiss and White [42] obtain from California data that lower-income households have a more elastic demand than households with medium to high incomes. From such data, we consider that vouchers can a priori be excluded as an effective instrument to fight energy poverty in California, while this is not the case for France.
} 
with the combined factors of market restructuring and/or environmental regulation towards nonrenewables, which is often behind the regulator's justification of vouchers. Finally, the assumption on the elasticity of the slope will ensure that firm profits are concave. This is admittedly a strong assumption, but its role is limited to rule out multiple market equilibria and, being sufficient but not necessary to this end, is not meant or used to describe consumers' behavior.

A consumer is said to be energy poor if her energy expenditure share equals or exceeds a given threshold $\alpha \cdot{ }^{27}$ Let $\theta_{\alpha}(p)$ be such that:

$$
\theta_{\alpha}(p)=\{\theta \mid p \hat{q}(p, \theta)=\alpha \theta\}
$$

i.e. $\theta_{\alpha}(p)$ is the energy poverty cut-off. With $\varepsilon(p, \theta)<1$, the set of energy poor consumers is $\Theta_{\alpha}(p) \equiv\left\{\theta: \theta \leq \theta_{\alpha}(p)\right\}$. From (1), we get:

$$
\theta_{\alpha}^{\prime}(p)=\frac{\hat{q}\left(p, \theta_{\alpha}(p)\right)}{\alpha} \frac{1-\eta\left(p, \theta_{\alpha}(p)\right)}{1-\varepsilon\left(p, \theta_{\alpha}(p)\right)}
$$

Then $\theta_{\alpha}^{\prime}(p) \gtrless 0$ iff $\theta_{\alpha}(p) \lessgtr \hat{\theta}(p)$ : if demand is inelastic at $\theta_{\alpha}(p)$, an increase in price raises the number of consumers that are energy poor because expenditure on energy is increased, while a decrease in price reduces the number of consumers that are energy poor. Although a case where $\theta_{\alpha}^{\prime}(p)<0$ would not seem sensible because it would mean that an increase in price would help reduce energy poverty, we cannot ex ante exclude it under the voucher scheme because the price, and thus the relationship between $\theta_{\alpha}(p)$ and $\hat{\theta}(p)$, is later determined endogenously in the model. We will, however, assume that the initial market condition under which the regulator wishes to introduce vouchers is characterized by $\theta_{\alpha}(p)<\hat{\theta}(p)$ or, equivalently, $\eta\left(p, \theta_{\alpha}(p)\right)<1$.

\subsection{Aggregate Demand and Energy Market Structure}

The energy industry is composed of $n$ identical firms that produce energy at a constant marginal cost $c$, which represents the marginal cost to produce and deliver a unit of energy to the consumer, i.e. the price that would result in the absence of any market power in the

\footnotetext{
${ }^{27}$ In practice, a common threshold is $\alpha=0.1$. This is, for instance, the threshold proposed by the seminal contribution of Boardman [7] and the one used in the voucher programs in France and South Korea. We implicitly assume here that this threshold is such that there exist consumers that exceed it and others that are below it. This excludes homothetic utility functions.
} 
whole chain of production. This cost can also include environmental taxes or other levies. Then, we treat firms "as if" they were vertically integrated in order to take into account that market power can be exercised at any level, most notably at the generation or the transmission stages in electricity rather than at the retail stage. The number $n$, which we use as an index of industry concentration, can then be taken as the reciprocal of the HHI under our hypothetical vertically integrated industry.

We assume that firms compete $\grave{a}$ la Cournot. The aggregate demand that the industry faces is denoted by $\hat{Q}(p)$ where $\hat{Q}(p) \equiv \int_{\underline{\theta}}^{\bar{\theta}} \hat{q}(p, \theta) d F$. We let $\hat{E}(p) \equiv-\hat{Q}^{\prime}(p) \frac{p}{Q}$ be the price elasticity of aggregate demand. The next Lemma shows that the assumption $1 \mathrm{c}$ ) on the elasticity of the slope of individual demand carries on to the slope of aggregate demand. ${ }^{28}$

Lemma $1 \hat{\Omega}(p) \equiv \frac{\hat{Q}^{\prime \prime}(p)}{\hat{Q}^{\prime}(p)} p \geq-2$

Lemma 1 ensures that a unique symmetric Cournot equilibrium exists. ${ }^{29}$ Then, the equilibrium price, which we denote $p_{0}$ and use as our benchmark market price, follows the usual inverse elasticity rule, i.e. $p_{0}$ is such that: ${ }^{30}$

$$
\hat{\mathcal{L}}\left(p_{0}\right)=\frac{1}{n \hat{E}\left(p_{0}\right)}
$$

where $\hat{\mathcal{L}}(p)=\frac{p-c}{p}$ is the Lerner index, an increasing concave function of $p$.

We make an assumption on this market equilibrium that allows us to rationalize a regulator's willingness to introduce vouchers as an instrument to fight energy poverty.

Assumption $2 \theta_{\alpha}\left(p_{0}\right)<\hat{\theta}(p)$, i.e. $\eta\left(p_{0}, \theta_{\alpha}(p)\right)<1$

This assumption implies that the energy poverty definition is such that all energy poor consumers have an inelastic demand before the introduction of vouchers. If their demand were elastic, a "solution" to reduce energy poverty would be to induce an increase in the energy price, as consumers with elastic demand would then reduce their energy expenditure. This would go against the stylized fact that high prices, whether caused by the lack of effective competition or the financing of a mandated portfolio of renewables, are behind the energy poverty phenomenon that the regulator wishes to counter.

\footnotetext{
${ }^{28}$ Proofs of the Lemma and Propositions are in the Appendix.

${ }^{29}$ See Anderson and Renaud [3], p. 256.

${ }^{30}$ This price condition is reminiscent of Bertoletti and Etro [6] and Foellmi and Zweimüller [20].
} 


\section{Vouchers}

\subsection{Consumer Behavior and Individual Demands}

Under a voucher program, a consumer receives an amount $t \geq 0$ of vouchers, ${ }^{31}$ which is the quantity of numeraire that is given to purchase energy only. Because the consumer utility function $U$ is strictly increasing, all allocated vouchers are necessarily used. We can then consider that the consumer's income is effectively $\theta+t$, but that her energy consumption is constrained to reach at least $\frac{t}{p}$ by the voucher program. For this reason, we define $\theta+t$ as total income $e^{32}$ and we write the problem as:

$$
\begin{array}{ll}
\max _{q, y} & U(q, y) \\
\text { s.t. } & \\
& p q+y \leq \theta+t \quad\left(\lambda_{\theta}\right) \\
& q \geq \frac{t}{p} \quad\left(\lambda_{t}\right)
\end{array}
$$

where $\lambda_{\theta}$ and $\lambda_{t}$ are Lagrange multipliers. We let $q(p, t, \theta)$ and $y(p, t, \theta)$ be the solutions of the problem, and $V(p, t, \theta)$ be the indirect utility function. By the envelope theorem, $V_{\theta}^{\prime}=\lambda_{\theta}$ and $V_{t}^{\prime}=\lambda_{\theta}-\frac{\lambda_{t}}{p}$ : if the constraint on voucher use is not binding $\left(\lambda_{t}=0\right)$, the voucher is as good as money; if it is binding, it has less value because of the requirement of consuming energy. Letting $\theta_{t}(p, t)$ be such that $\hat{q}\left(p, \theta_{t}(p, t)+t\right)=\frac{t}{p}$, the consumer's demand functions are:

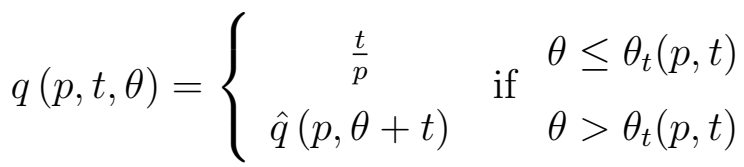

If $\theta \leq \theta_{t}(p, t)$, the quantity of energy obtained through vouchers, $\frac{t}{p}$, is greater than the optimal energy consumption with total income $\theta+t$ : we then say that energy consumption is voucher-based. If $\theta>\theta_{t}(p, t)$, the consumer uses more energy than the voucher allocation: the consumer does not feel constrained by vouchers and energy consumption corresponds to the optimal choice with income $\theta+t$. We then say that energy consumption is free.

The voucher program targets the share of income spent on energy. While there is a debate in the literature on an appropriate concept of income to use in the computation of

\footnotetext{
${ }^{31}$ Then, $t=0$ represents a case where the consumer is not eligible for vouchers.

${ }^{32} \mathrm{As} U$ is strictly increasing, the budget constraint is tight at the optimal solution, so that the total expenditure of the consumer is $\theta+t$.
} 
this share, ${ }^{33}$ in our framework, total income $\theta+t$ is the relevant basis because it constitutes the total expenditure of the consumer in any circumstances. Accordingly, we define the energy expenditure share of total income (or of total expenditure) from (5):

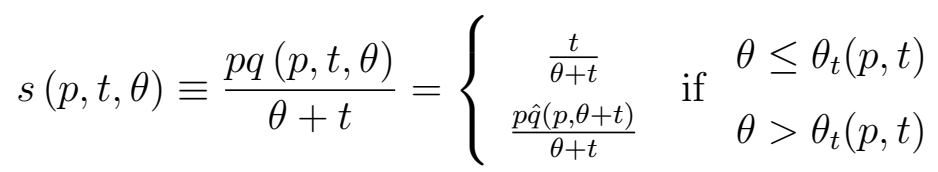

The following Lemma describes the properties of this function under Assumptions 1 and 2 .

Lemma 2 Under Assumptions 1 and 2,

a) $s_{\theta}^{\prime}(p, t, \theta)<0, \forall \theta \in \Theta$

b) $s_{p}^{\prime}(p, t, \theta)=0$ if $\theta<\theta_{t}(p, t)$ and $s_{p}^{\prime}(p, t, \theta) \gtrless 1$ as $\eta \lessgtr 1$ if $\theta>\theta_{t}(p, t)$

c) $s_{t}^{\prime}(p, t, \theta)>0$ if $\theta<\theta_{t}(p, t)$ and $s_{t}^{\prime}(p, t, \theta)<0$ if $\theta>\theta_{t}(p, t)$

Part $a$ ) is a direct consequence of the fact that energy is assumed to be an essential good. Part $b$ ) and $c$ ) distinguish voucher-based consumption and free consumption. Under free consumption $\left(\theta>\theta_{t}(p, t)\right)$, part $\left.b\right)$ comes from the fact that an increase in price induces an increase (decrease) in expenditure if demand is inelastic (elastic), while part $c$ ) reproduces the part $a$ ) result since vouchers are identified to income. For voucher-based consumers $\left(\theta<\theta_{t}(p, t)\right)$, the expenditure share is $\frac{t}{t+\theta}$ and is thus independent of the price, but more importantly, an increase in the voucher allocation increases the energy expenditure share. This situation points to the possibility of an "overshooting" of the policy if the aim of vouchers is to reduce the energy expenditure share: voucher-based consumers clearly detain too many vouchers.

\subsection{Aggregate Demand}

Under the voucher scheme $\mathbf{t}=\{t(\theta)\}_{\theta \in \Theta}$, the aggregate demand that the industry faces is given by:

$$
Q(p, \mathbf{t}) \equiv \int_{\underline{\theta}}^{\bar{\theta}} q(p, t(\theta), \theta) d F=\int_{\Theta_{f}} \hat{q}(p, \theta+t(\theta)) d F+\int_{\Theta_{v}} \frac{t(\theta)}{p} d F
$$

\footnotetext{
${ }^{33}$ See, for instance, Hills [22] and Moore [36].
} 
where $\Theta_{f}$ denotes the set of income levels for which consumption is free, while $\Theta_{v}$ is the set of income levels for which consumption is voucher-based. ${ }^{34}$ Letting $Q_{\Theta_{i}}(p, \mathbf{t})=$ $\int_{\Theta_{i}} q(p, t(\theta), \theta) d F$, where $\Theta_{i}=\Theta_{f}, \Theta_{v}$, the elasticity of demand is then:

$$
E(p, \mathbf{t})=\sum_{\Theta_{i}} \frac{Q_{\Theta_{i}}(p, \mathbf{t})}{Q(p, \mathbf{t})} E_{\Theta_{i}}(p, \mathbf{t})
$$

As each consumer in $\Theta_{t}$ has an individual demand elasticity of 1 , the aggregate elasticity of demand is:

$$
E(p, \mathbf{t})=\left(1-\frac{Q_{\Theta_{f}}}{Q}\right)+\frac{Q_{\Theta_{f}}}{Q} E_{\Theta_{f}}(p, \mathbf{t})
$$

Note that the presence of vouchers does not jeopardize the existence and uniqueness of a Cournot equilibrium.

Lemma 3 Let $\Omega(p, \mathbf{t}) \equiv \frac{Q_{p}^{\prime \prime}}{Q_{p}^{\prime}} p$ be the elasticity of the demand slope under the voucher system. Then $\Omega(p, \mathbf{t}) \geq-2$.

This price equilibrium $p_{v}(\mathbf{t})$ then follows the inverse elasticity rule:

$$
\mathcal{L}\left(p_{v}(\mathbf{t})\right)=\frac{1}{n E\left(p_{v}(\mathbf{t}), \mathbf{t}\right)}
$$

The price elasticity of aggregate demand and the Lerner index thus depend on the whole voucher path $\{t(\theta)\}_{\theta \in \Theta}$. If we make a marginal variation of the voucher level for a given $\theta$, i.e. $d t(\theta)>0$, other things being equal, the corresponding marginal variation is obtained from (8):

$$
\left[\mathcal{L}^{\prime}\left(p_{v}\right)+\frac{E_{p}^{\prime \prime}\left(p_{v}, \mathbf{t}\right)}{n E\left(p_{v}, \mathbf{t}\right)^{2}}\right] \frac{\partial p_{v}}{\partial t(\theta)}=-\frac{\frac{\partial E\left(p_{v}, \mathbf{t}\right)}{\partial t(\theta)}}{n E\left(p_{v}, \mathbf{t}\right)^{2}}
$$

Because the terms in brackets are positive, $\frac{\partial p_{v}}{\partial t(\theta)}$ has the opposite sign of $\frac{\partial E\left(p_{v}, \mathbf{t}\right)}{\partial t(\theta)}$. We thus wish to determine whether the marginal variation $d t(\theta)$ increases or decreases the elasticity to determine its impact on price.

Lemma $4 \quad$ a) For an interior point of $\Theta_{f}$, we have:

$$
\frac{\partial E(p, \mathbf{t})}{\partial t(\theta)}=\frac{[\eta(p, \theta+t(\theta))-E(p, \mathbf{t})] \hat{q}_{t}^{\prime}+\hat{q}(p, \theta+t(\theta)) \eta_{t}^{\prime}}{Q} f(\theta)
$$

where $\hat{q}_{t}^{\prime}$ stands for $\frac{\partial \hat{q}(p, \theta+t(\theta))}{\partial t(\theta)}$ and $\eta_{t}^{\prime}$ for $\frac{\partial \eta(p, \theta+t(\theta))}{\partial t(\theta)}$.

\footnotetext{
${ }^{34}$ Note that because $\mathbf{t}$ is arbitrary and allows any non-negative transfer path $\{t(\theta)\}$, sets $\Theta_{f}$ and $\Theta_{v}$ are not necessarily connected.
} 
b) For an interior point of $\Theta_{v}, \frac{\partial E(p, \mathbf{t})}{\partial t(\theta)}=0$.

c) At a frontier point $\theta$ of $\Theta_{f}$ and $\Theta_{v}$,

$$
\frac{\partial E(p, \mathbf{t})}{\partial t(\theta)} \lessgtr 0 \text { as } \eta \gtrless 1
$$

Expression (10) has an ambiguous sign because $\eta(p, \theta+t(\theta))-E(p, \mathbf{t})$ can be positive as well as negative. There are two effects: an elasticity effect, $\frac{\hat{q}}{Q} \eta_{t}^{\prime}$, and a quantity effect, $(\eta-E(p, \mathbf{t})) \frac{\hat{q}_{t}^{\prime}}{Q}$. The elasticity effect is positive because the transfer increment raises the elasticity of demand of consumers that receive them. The quantity effect comes from increased consumption of beneficiaries of the transfer increment: because of the increased weight of these beneficiaries, this effect increases or decreases the elasticity depending on whether their initial price elasticities are above or below the average (aggregate) elasticity.

The upshot is that the introduction of vouchers in imperfect competitive markets can have intricate consequences on the price elasticity of aggregate demand. The fact that offering vouchers to some consumers increases their price elasticity of individual demand does not allow us to predict an increase in the elasticity and thus, a decrease in price. The regulator must also take into account the price elasticity of the voucher recipients demand relative to aggregate price elasticity.

Furthermore, note that the approach taken in (10) is not valid if there is a change of transfers for a mass of consumers, particularly a change $\{d t(\theta)\}_{\Theta}$, because there is no fixed reference point $E(p, \mathbf{t})$ to which we can compare an individual $\eta(p, \theta+t(\theta))$ when we consider that all $t(\theta)$ move simultaneously. However, it will turn out that if the mass of consumers that receive vouchers have similar characteristics, the impact on elasticity can in fact be easier to compute.

\subsection{Regulator's Problem}

In our positive view, we take as given the regulator's policy to distribute vouchers with the aim of eliminating cases where consumers spend more than a given share of their income on energy. We add the objective that this distribution be made at least cost, as it seems to be 
a sensible objective whatever the reason behind the introduction of vouchers. As a result, given the energy price $p$ imposed by the market, the regulator's problem is:

$$
\begin{array}{ll}
\min _{\{t(\theta) \geq 0\}} & \int_{\underline{\theta}}^{\bar{\theta}} t(\theta) d F \\
& \text { s.t. } \\
& s(p, t(\theta), \theta) \leq \alpha, \forall \theta
\end{array}
$$

where we assume that the regulator's energy expenditure target $\alpha$ is such that $s(p, 0, \underline{\theta})>\alpha$ and $s(p, 0, \bar{\theta})<\alpha$ to ensure practical relevance to the policy. ${ }^{35}$

This problem is straightforward to solve. We first note that an optimal solution cannot be such that $s_{t}^{\prime}>0$, as decreasing $t$ would both decrease transfer payment and relax the constraint. From Lemma 2 c), this excludes voucher-based consumption. Consequently, at the optimal solution, all consumers enjoy free consumption with income $\theta+t(\theta)$. With $s_{t}^{\prime} \leq 0$, the poverty constraint $s \leq \alpha$ must be binding at optimum for all $\theta \leq \theta_{\alpha}(p)$. We thus have the following result:

Lemma 5 For a given $p$, the optimal voucher policy is,

$$
t^{*}(\theta, p)=\max \left\{\theta_{\alpha}(p)-\theta, 0\right\}
$$

At $t^{*}(\theta, p), \Theta_{v}=\varnothing$, i.e. there are no voucher-based consumers.

Under this optimal policy, individual consumption is $q^{*}(\theta, p)=q\left(p, t^{*}(\theta), \theta\right)$. Figures 1 and 2 depict this policy (plain line) in comparison with the no voucher case (dotted line).

$$
\begin{aligned}
& \text { [ Insert Figure } 1 \text { here ] } \\
& \text { [ Insert Figure } 2 \text { here ] }
\end{aligned}
$$

We see that the quantity of vouchers distributed decreases with income for $\theta \leq \theta_{\alpha}(p)$ (Figure 1$)$. Consumers with basic income $\underline{\theta}$ receive the maximal amount of energy vouchers.

\footnotetext{
${ }^{35}$ If $s(p, 0, \underline{\theta})<\alpha$, each consumer already meets the expenditure target, and the solution is $t(\theta)=0, \forall \theta$. If $s(p, 0, \bar{\theta})>\alpha$, all consumers would receive vouchers, which suggests an excessively stringent target with respect to market conditions.
} 
The voucher policy $t^{*}(\theta, p)$ can also be seen as the regulator's reaction function. From (12), we have:

$$
\frac{\partial t^{*}(\theta, p)}{\partial p}=\left\{\begin{array}{cl}
\frac{\hat{q}\left(p, \theta_{\alpha}(p)\right)}{\alpha} \frac{1-\eta\left(p, \theta_{\alpha}(p)\right)}{1-\varepsilon\left(p, \theta_{\alpha}(p)\right)} \geq 0 & \text { if } \theta \leq \theta_{\alpha}(p) \\
0 & \text { if } \theta>\theta_{\alpha}(p)
\end{array}\right.
$$

Under Assumptions 1 and 2, we obtain the intuitive result that an increase in energy price requires an increase in the amount of vouchers to avoid the reappearance of energy poverty.

We thus see that for a given price, vouchers seem a particularly simple instrument to implement. This is probably the representation of the system that regulators have in mind when vouchers are implemented. This representation seems fairly accurate when the targeted good is supplied in highly competitive markets. However, in a concentrated market such as the energy sector, a reaction from the part of suppliers is to be expected.

\section{The Voucher Game}

We now turn to the price impact of implementing vouchers in an imperfectly competitive market, where firms compete à la Cournot. To determine this impact, we model a game between the regulator and the energy industry firms. We consider three settings: $(i)$ the regulator and the industry's firms make simultaneous decisions, (ii) the regulator moves first, and (iii) the firms move first.

\subsection{Nash Equilibrium}

We first consider the Nash equilibrium where both the regulator and the energy firms are involved in a simultaneous decision-making process: none of them has a commitment power that enables it to announce first its decision and stick to it. 
Consider a Nash equilibrium $\left(p_{n}, \mathbf{t}_{n}\right)$, where $\mathbf{t}_{n}=\left\{t_{n}(\theta)\right\} .{ }^{36}$ From the best replies $(8)$ and (12), it must satisfy simultaneously:

$$
\begin{aligned}
t_{n}(\theta) & =t^{*}\left(\theta, p_{n}\right) \\
p_{n} & =p_{v}\left(\mathbf{t}_{n}\right)
\end{aligned}
$$

From Lemma 5, the best-response of the regulator to $p_{n}$ entails that all consumers enjoy free consumption, so we must have $\Theta_{v}=\varnothing$, while $\Theta_{f}$ can be partitioned in two subsets, $\Theta_{t}=\left[\underline{\theta}, \theta_{\alpha}\left(p_{n}\right)\right]$ and $\Theta_{0}=\left[\theta_{\alpha}\left(p_{n}\right), \bar{\theta}\right]$, representing income levels that make consumers eligible to transfers according to $\left\{t_{n}(\theta)\right\}$, and those who are not, respectively. Consumers receiving vouchers all reach a total income equal to $\theta_{\alpha}\left(p_{n}\right)$.

In order to compare $p_{n}$ with $p_{0}$, we wish to compare the elasticity of aggregate demand before and after the introduction of vouchers. As the quantity demanded at equilibrium is given by:

$$
Q\left(p_{n}, \mathbf{t}_{n}\right)=\alpha F\left(\theta_{\alpha}\left(p_{n}\right)\right) \frac{\theta_{\alpha}\left(p_{n}\right)}{p_{n}}+\int_{\Theta_{0}} \hat{q}\left(p_{n}, \theta\right) d F
$$

the equilibrium price elasticity of aggregate demand is:

$$
E^{n}\left(p_{n}, \mathbf{t}_{n}\right)=\frac{Q_{\Theta_{t}}}{Q} \eta\left(p_{n}, 0, \theta_{\alpha}\left(p_{n}\right)\right)+\frac{Q_{\Theta_{0}}}{Q} E_{\Theta_{0}}\left(p_{n}, 0\right)
$$

Note that consumers in $\Theta_{0}$ have the same elasticity of demand before and after the introduction of vouchers for a given price because they receive no vouchers. Note also that after the introduction of vouchers, all consumers in $\Theta_{t}$ have the same elasticity of demand i.e. $\eta\left(p_{n}, \theta+t_{n}(\theta)\right)=\eta\left(p_{n}, \theta_{\alpha}\left(p_{n}\right)\right)$. However, as $\hat{\eta}_{\theta}^{\prime}(p, \theta)>0$ for any $p$, we have $\eta\left(p, \theta_{\alpha}(p)\right)>\eta(p, \theta), \forall \theta \in \Theta_{t}$. These two facts jointly imply that the overall elasticity increases; therefore, we obtain the following result.

Proposition 1 Under simultaneous decision making, the introduction of vouchers reduces the energy price, i.e. $p_{n}<p_{0}$.

\footnotetext{
${ }^{36}$ If we assume upper bounds for both $\{t(\theta)\}$ and $p$, the strategy sets are compact; then, the facts that the objective functions are quasi-concave for the case of the firms and linear for the case of the regulator ensure the existence of the equilibrium (Dasgupta and Maskin [16]). These are realistic assumptions: an upper bound on the price can result from a consumer reserve price for energy, while an upper bound on the transfers can reflect a governmental budget constraint. We also assume that these bounds are sufficiently high so that the equilibrium is an interior one.
} 
In a nutshell, the fact that vouchers increase the elasticity of a mass of consumers (rather than at a point as in (10)) increases the elasticity of demand that the industry faces at any given price. As a result, the firms' best response is a lower price.

The result may seem surprising in view of the fact that vouchers are good-specific, so that vouchers themselves seem to create a segment of energy demand that is perfectly inelastic, giving an opportunity to firms to increase the price. This intuition fails because it is never in the interest of the regulator to have voucher-based consumption. In reality, vouchers are not energy related but instead represent income distribution. Because the problem perceived by the regulator is too much spending on energy, the intent can be seen to increase the consumption of the numeraire in a greater proportion than energy: people are considered poor because their consumption basket does not contain enough goods other than energy. Rather than increasing the firms' market power, vouchers reduce the necessary nature of energy of a large group of consumers, i.e. reduce the price elasticity of aggregate demand.

\subsection{Industry as a First Mover}

When the industry moves first, it can anticipate the regulator's emission of vouchers and the demand it faces is given by $Q\left(p, \mathbf{t}^{*}(\theta, p)\right)$. Although this demand function has the form given in (14), firms now take into account the indirect impact of the price on demand through the income effect of allocated vouchers, so that the impact of a change of price on the quantity demanded and the elasticity is different than under the simultaneous case. In fact, firms exploit the voucher scheme to make the demand less elastic.

Lemma 6 Let $E^{s}\left(p, \mathbf{t}^{*}(\theta, p)\right)=-\frac{d Q\left(p, \mathbf{t}^{*}(\theta, p)\right)}{d p} \frac{p}{\left(p, \mathbf{t}^{*}(\theta, p)\right)}$ be the price elasticity of demand when the indirect effect of a price change through the voucher allocation is taken into account. Then $E^{s}\left(p, \mathbf{t}^{*}(\theta ; p)\right)<E^{n}(p, \mathbf{t})$.

The intuition behind the result is the following. An increase in price has the direct effect of decreasing the aggregate quantity demanded. This effect is taken into account in the Nash equilibrium. However, firms foresee that the regulator will react to this increase by raising the total income of eligible consumers (consumers with $\theta \leq \theta_{\alpha}(p)$ ) to maintain their energy expenditure share. This tends to increase the quantity demanded so that the total effect on quantity demanded is less important with both the direct and indirect effects than with 
the sole direct effect. ${ }^{37}$ In other words, if measured at a common price, the price elasticity of demand is lower in the game where firms move first than in the one where decisions are simultaneous.

Combining this result with the market equilibrium condition (8), we obtain the following Proposition.

Proposition 2 When the voucher policy is made in reaction to the industry price, the industry as a leader increases its price with respect to the Nash equilibrium price, i.e. $p_{s}>p_{n}$. This implies, in turn, that $\theta_{\alpha}\left(p_{s}\right)>\theta_{\alpha}\left(p_{n}\right)$ and that $t^{*}\left(\theta, p_{s}\right) \geq t_{n}(\theta)$ for all $\theta \leq \theta_{\alpha}\left(p_{s}\right)$.

This proposition follows the fact that, as shown in Lemma 6, leadership makes firms perceive the demand as being less elastic than in the simultaneous moves game. As a direct result, the price increases, the set of eligible consumers is enlarged and transfers are increased. This result is illustrated in Figure 3.

\section{[Insert Figure 3 here]}

Note that, compared to the benchmark case with no vouchers, the price effect of vouchers with firms moving first is ambiguous: it will depend on whether the perceived elasticity of eligible consumers with vouchers is greater than or less than their initial elasticity.

Corollary 1 When the energy industry firms move first, the introduction of vouchers can increase as well as decrease the price.

Thus, it is possible that the introduction of vouchers brings a price increase, but this would require that firms are able to commit to a price before the implementation. Such a commitment seems unlikely, but not to be excluded if the industry is highly concentrated and near monopolistic. The next case with the regulator committing first to a policy may seem more plausible.

\subsection{Regulator as a First Mover}

When the regulator moves first, it takes into account the firms' response when it determines the transfer path $t=\{t(\theta)\}_{\theta \in \Theta}$. The regulator then solves the problem (11) where $p=p_{v}(\mathbf{t})$

\footnotetext{
${ }^{37}$ In fact, we cannot exclude the case where this indirect effect more than compensates for the direct effect so that the increase in price entails an increase in quantity demanded of eligible consumers.
} 
so that each voucher allocated to a consumer will have an impact on the market price as depicted in (9). Note that the regulator can always settle to the Nash equilibrium by allocating $\mathbf{t}_{n}$; therefore, we obtain the following proposition.

Proposition 3 Let $p_{r}$ be the market equilibrium price when the regulator moves first. Then $p_{r} \leq p_{n}$.

Now, for a decrease in price to be possible, there must exist a path $\mathbf{t}_{r}=\left\{t_{r}(\theta)\right\}_{\theta \in \Theta}$ such that $\int_{\Theta} t_{r}(\theta) d F<\int_{\Theta} t_{n}(\theta) d F$ and $p_{v}\left(\mathbf{t}_{r}\right)<p_{n}$. This fact implies that for $\theta$ below $\theta_{\alpha}\left(p_{n}\right)$, consumers have a higher quantity demanded with $\mathbf{t}_{r}$, but since they have an inelastic demand, the reduction in price implies that their energy expenditure share is decreased. This, in turn, implies that $\theta_{\alpha}\left(p_{v}\left(\mathbf{t}_{r}\right)\right)<\theta_{\alpha}\left(p_{n}\right)$. To have such a result, it requires that some vouchers be given to consumers with $\theta>\theta_{\alpha}\left(p_{n}\right)$ in such a way that the overall elasticity of demand is sufficiently increased and that the reduction in vouchers to consumers below $\theta_{\alpha}\left(p_{n}\right)$ is greater than the increase in vouchers to consumers above $\theta_{\alpha}\left(p_{n}\right)$. Such a hypothetical case is illustrated in Figure 4, where the surface between the straight lines is greater than the surface under the "bulge".

\section{[Insert Figure 4 here]}

However, the impact of a change of the whole transfer path $\{t(\theta)\}$ is very difficult to derive. ${ }^{38}$ In other words, the properties of the reaction function $p_{v}(\mathbf{t})$ cannot be characterized so that the properties of $\left\{t_{r}(\theta)\right\}$ cannot be made more precise than the fact that whenever $p_{r}<p_{n}$, we must have $t_{r}(\theta)<t_{n}(\theta)$ for $\theta<\theta_{\alpha}\left(p_{n}\right)$ and $t_{r}(\theta) \geq 0$ for $\theta \geq \theta_{\alpha}\left(p_{n}\right)$.

Note also that this solution implies that some relatively poor consumers can receive less transfers than richer consumers, i.e. there exist income levels $\theta$ and $\theta^{\prime}$ such that $\theta<\theta^{\prime}$ and $t(\theta)<t\left(\theta^{\prime}\right)$. Such redistribution can be politically infeasible. If the regulator is constrained to make transfers that decrease with income ${ }^{39}$ there is no possibility to improve on the Nash equilibrium.

\footnotetext{
${ }^{38}$ Note that equation (10) gives the impact of a change in $t(\theta)$ around a single given point $\theta$, while the regulator is allowed to change $t(\theta)$ at any point simultaneously. In a general setting, we cannot determine whether the relative weight of an individual's consumption in aggregate demand increases or decreases following the change; therefore, we cannot determine the impact on the aggregate demand elasticity even when we know the impact on the individual elasticity.

${ }^{39}$ Indeed, in the French program, the face value of energy vouchers (all taxes included) decrease with income. The details are given in the Appendix.
} 
Proposition 4 If constraint $t^{\prime}(\theta) \leq 0$ is added to problem (11), then $\mathbf{t}_{r}=\mathbf{t}_{n}$ and $p_{r}=p_{n}$.

The intuition behind this result is that under transfers that decrease with income, any reduction of transfers from the Nash equilibrium is counterproductive because it makes the demand of eligible consumers less elastic and entails that the firms react with a price increase.

\section{Discussion}

In our positive approach, we use the same measure of energy poverty as the ones in the French and South Korean voucher programs. Although this measure corresponds to the original one proposed by Boardman [7], in fact, "there is no common definition or standardized indicator for assessing fuel poverty" (Charlier and Legendre [9]). Thomson et al. [45] classify proposed methods of measurement in three approaches: " $(i)$ [the e]xpenditure approach where examinations of the energy costs faced by households against absolute or relative thresholds provide a proxy for estimating the extent of domestic energy deprivation; ( $i i$ ) [the c]onsensual approach - based on self-reported assessments of indoor housing conditions, and the ability to attain certain basic necessities relative to the society in which a household resides, and (iii) the [d]irect measurement - where the level of energy services (such as heating) achieved in the home is compared to a set standard". Clearly, the Boardman definition used by the French and South Korean programs is part of the first approach. In this section, we argue that our framework is general enough to make our results independent of the energy poverty measure that is used to the extent that this measure is exclusively related to income and the energy price. We also discuss the extension that is necessary to make whenever the measure is also dependent on the energy efficiency of the consumers' dwellings.

Assume that a voucher program uses a direct measurement of energy poverty such as the one proposed by Faiella and Lavecchia [17], who estimate for Italy the "inability to buy a minimum basket of energy services". Letting $\underline{q}$ represent this minimal level of energy services, a consumer is then energy poor if $\theta \leq \underline{\theta}(p) \equiv p q{ }^{40}$ As long as Assumptions 1 and 2 are maintained, it is straightforward to see that our analysis is preserved: replacing the constraint of problem (11) by $\theta \leq \underline{\theta}(p)$, one directly obtains the regulator's best-response

\footnotetext{
${ }^{40} \mathrm{An}$ individual in this situation is called an "under-consumer" by Miniaci et al. [35] to contrast this type of deprivation to others where the expenditure share exceeds the threshold but where the minimum basket of energy services is nevertheless reached.
} 
$t^{*}(\theta, p)=\max \{\underline{\theta}(p)-\theta, 0\}$, which has the same form as (12). If the regulator simultaneously uses a direct measure and an energy expenditure share measure, then the best-response depends on the measure that proves to be the regulator's binding constraint, i.e. $t^{*}(\theta, p)=$ $\max \left\{\theta_{\alpha}(p)-\theta, \underline{\theta}(p)-\theta, 0\right\}$. The same kind of treatment can be made if the program wishes to fight "absolute poverty" where a consumer "cannot afford the minimum standard of energy and or other goods at the same time." (Miniaci et al. [35], p. 291). Then, one has to define a minimal level of the numeraire $\underline{y}$ and $\underline{\theta}(p)$ in the previous expression is replaced by $p \underline{q}+\underline{y}$. If the regulator wishes to use the notion of "residual income", where the affordability problem is defined as insufficient "financial resources to fund a minimum level of consumption of other goods after paying bills for gas and electricity" (Miniaci et al. [35], p. 291), poverty is defined by $\theta-p \hat{q}(p, \theta) \leq \underline{y}$, i.e. $y(p, \theta) \leq \underline{y} \cdot \underline{\theta}(p)$ is then such that $\hat{y}(p, \underline{\theta}(p))=\underline{y}$.

However, as the direct approach "attempts to measure if sufficient levels of energy services are being achieved in the home, such as heating and lighting" (Thomson et al. [45], p. 887), energy poverty measured along this approach is negatively correlated not only with income but also with the energy efficiency of dwellings. The same is true for the consensual approach, whose primary benefit is to seize the importance of energy efficiency (Thomson et al. [45], p. 885). Using a measure based only on the share of income devoted to energy expenditures then brings an identification problem ${ }^{41}$ between the consumers' preferences and the constraints they face with respect to energy efficiency. For the same income, we can have two households that consume the same amount $q>\underline{q}$ of energy, but one with energy efficient equipment that allows him to consume the numeraire in quantity $y>\underline{y}$ and another with equipment that restricts its numeraire of consumption to $y<\underline{y}$. Miniaci et al. [35] classify the latter as an "over-consumer" of energy ${ }^{42}$. To take into account such cases, an extension of our model that explicitly includes energy efficiency is required.

Such an extension is possible by considering, as in Crampes and Lozachmeur [12] and Levinson [28], a domestic production function of energy service $q=f(e, \mu)$, where $e$ is the energy consumed and $\mu$ is the efficiency of the energy equipment. The utility function remains a function of $q$, but individual demand functions are defined over the intermediate goods $e$ and $\mu$ as well as the numeraire $y$. The choice of energy service could then be modeled in two steps: the first would consist of finding the couple $(e, \mu)$ that minimizes the

\footnotetext{
${ }^{41}$ We thank a referee for raising the potential importance of this problem.

${ }^{42}$ If $\underline{q}$ is defined for an equipment with average efficiency, there could also exist the case of "underusers" who "demand less energy because their accommodation and electrical apparels are more efficient than standard ones" (Miniaci et al [35], p. 291). Then, voucher distribution based on $\underline{q}$ would oversubsidize such consumers.
} 
cost of obtaining an arbitrary energy service level $q$, i.e. to determine the energy service cost function $C\left(q ; p_{e}, p_{\mu}\right)$, where $p_{e}$ is the price of energy and $p_{\mu}$, the price of energy efficiency; the second would be to determine the utility maximizing $q$ given the consumer's income. One can also define a short-term cost function $C\left(q ; p_{e}, p_{\mu}, \mu\right)$, where $\mu$ is fixed, for a class of consumers $\Theta_{\mu}$ that do not control energy efficiency (e.g. tenants). Energy poor households that "over-consume" are such that $\theta \in \Theta_{\mu}, \theta \leq \theta_{\alpha}\left(p_{e}, p_{\mu}, \mu\right)$ and $y\left(p_{e}, p_{\mu}, \mu\right) \leq \underline{y}$. Then, if the regulator wishes to confront the overconsumption problem within the voucher program, it transfers $t^{*}\left(\theta, p_{e}, \mu\right)=\max \left\{\theta_{\alpha}(p, \mu)-\theta, \underline{\theta}(p, \mu)-\theta, 0\right\}$ for consumers in $\Theta_{\mu}$. This, however, requires information on the (in)capacity of the consumers to choose the level of $\mu$.

In this generalized model, if we assume a fixed $p_{\mu}$, our results should follow to the extent that the elasticity of the energy service demand with respect to $p_{e}$ satisfies Assumption 1 b). ${ }^{43}$ Further assumptions on the cross-effects of $p_{e}$ and $p_{\mu}$ as well as on the market structure of the energy efficiency market would, however, be needed in order to allow $p_{\mu}$ to be variable and market determined. This topic is left to future research. However, the principles outlined in our model should carry on in this more complex context: if the distribution of vouchers make the aggregate demand of energy more elastic, we should observe a reduction in the price of energy when the regulator moves first or when the regulator and the firms move simultaneously.

\section{Conclusion}

Our analysis shows that the introduction of vouchers in an oligopolistic market brings a price reduction of the targeted good if the regulator emits vouchers before or at the same time that the firms determine their output supply. The reason is that, to make the vouchers reduce the energy expenditure share of consumers, the regulator must allocate vouchers to low-income consumers that have inelastic demand and that this allocation increases the price elasticity of aggregate demand and thus reduces the firms' market power.

This result extends the theoretical work on the price effects of vouchers. Bradford and Shaviro [8] show that "the effect of the [voucher] program depends on the income and price elasticities of demand by beneficiaries and nonbeneficiaries, as well as on the price (and perhaps income) elasticity of supply". Our contribution is to use suitable assumptions on

\footnotetext{
${ }^{43} \mathrm{~A}$ fixed $p_{\mu}$ could correspond to a perfectly competitive market for energy efficiency, which seems reasonable because markets for energy efficiency (insulation, furnace equipment, etc.) seem fairly competitive.
} 
income and price elasticities in order to precise these results for oligopolistic markets. This approach allows us to anticipate the price impact of vouchers in the energy sector, in which voucher programs are a recent phenomenon.

Our analysis is motivated by the implementation of the French and South Korean energy voucher programs, which are characterized by high concentration. High concentration is still observed in many countries, but continuing regulatory efforts, notably at the retail level, make quite possible that market power becomes less and less important in the future. ${ }^{44}$ Through the use of parameter $n$, our model applies to any market structure spanning from monopoly $(n=1)$ to perfect competition $(n \rightarrow \infty)$. However, the greater $n$ is, the lower is the price markup before the introduction of vouchers. ${ }^{45}$ There is thus less scope for a price decrease when concentration is low. At the limit, vouchers would not have any price impact in a perfectly competitive market and its capacity to contain market power becomes immaterial. An interesting extension of our analysis would be to make comparative statics of the energy price with respect to $n$ in the presence of vouchers and compare the result with no vouchers in order to evaluate how the efficiency impact of vouchers changes with $n$. This extension is left to future research because of the complexity of determining the impact of vouchers on the size of the change of the price elasticity rather than only on the sign of this change. For the moment, note that our model has still relevance even in the perfectly competitive case because, for such a case, it implies that vouchers can be used as a redistributive instrument without being distortionary. ${ }^{46}$

We also use the energy poverty definition from the French and South Korean voucher programs, but the literature on energy poverty criticizes this definition. ${ }^{47}$ As mentioned in Section 6, an extension of the model would be to include a domestic production function that takes into account energy efficiency along with energy consumption to determine the energy

\footnotetext{
${ }^{44}$ For instance, CEER [13] reports about electricity retail markets that "[c]omparing 2016 and 2017, it is noted that there has been an overall decrease in the EU HHIs related to a market competition increase". In particular, for Great Britain, "[i]n December 2017, there were 69 active licensed suppliers in the domestic retail market, mainly active in both electricity and gas. This is a net increase of 17 active domestic suppliers since December 2016".

${ }^{45}$ Technically, to obtain $\frac{\partial p}{\partial n}<0$ in all cases, we should reinforce our assumption 1 c) to $\omega(p, \theta) \geq-1$ in order to obtain $\Omega(p, \theta) \geq-1$. (See Seade [43]).

${ }^{46}$ For instance, in countries where the marginal cost is still high because of the fundamentals of energy supply and/or efficient but high pigouvian taxes on emissions, the primary distributive role of vouchers still exists.

${ }^{47}$ See Hills [22].
} 
service obtained. This extension would allow us to compare the price impact of vouchers when vouchers are allocated according to other energy poverty definitions.

Finally, our approach is positive. An extension of our work would be to analyze normative properties of vouchers. The fact that the program has the potential to reduce price and thus to enhance the industry allocative efficiency can be a start for a potential normative justification. However, to provide such a justification, we first would have to model the way these vouchers are financed. Second, as the regulator obviously has equity concerns when implementing vouchers, it would also require the formulation of a welfare objective that includes a measure of inequality aversion. The work of Poudou and Roland [41] on the welfare properties of universal service could be a starting point. In our present framework, welfare results are ambiguous in terms of a utilitarian welfare function because we do not evaluate the loss of a price decrease in terms of the opportunity cost of financing the program and of the firms' profit loss.

\section{References}

[1] ADEME (Agence de l'environnement et de la maîtrise de l'énergie) (2018). La précarité énergétique. Accessed June 18th, 2019.

https://www.ademe.fr/expertises/batiment/quoi-parle-t/precarite-energetique,

[2] ANRC (African Natural Resources Center) (2017). Gas Domestication in South Korea: Lessons for African Countries.

www.afdb.org/fileadmin/uploads/afdb/Documents/Publications/anrc.

[3] Anderson, S. P. and R. Renault (2003). "Efficiency and Surplus Bounds in Cournot Competition." Journal of Economic Theory 113 (2): 253-264.

[4] Bakaloglou, S. and D. Charlier (2018). "Energy Consumption in the French Residential Sector: How Much Do Individual Preferences Matter?" FAERE Working Paper 2018.05.

[5] Bank of Canada, Annual Exchange Rates. Accessed December 8th, 2019. www.bankofcanada.ca/rates/exchange/annual-average-exchange-rates/.

[6] Bertoletti P. and F. Etro (2017). "Monopolistic Competition when Income Matters." Economic Journal 127 (August): 1217-1243. 
[7] Boardman, B. (1991). Fuel Poverty: From Cold Homes to Affordable Warmth. London: Belhaven Press.

[8] Bradford, D. and D. Shaviro (2000). The Economics of Vouchers. In Steurle, C. E., Ooms, V. D., Peterson, G. E. and R. D Reischauer (eds.), Vouchers and the Provision of Public Services, Washington: Brookings Institution Press.

[9] Charlier, D. and B. Legendre (2019). "A Multidimensional Approach to Measuring Fuel Poverty." The Energy Journal, 40 (2): 27-51.

[10] Chaton, C. and E., Lacroix (2018). "Does France Have a Fuel Poverty Trap?" Energy Policy 113: 258-268.

[11] Chester, L. and A. Morris (2011). "A New Form of Energy Poverty Is the Hallmark of Liberalized Electricity Sectors." Australian Journal of Social Issues, 46 (4): 435-459.

[12] Crampes, C. and J.-M. Lozachmeur (2012). "Tarif progressif, efficience et équité, chapitre 2 : redistribution et distorsions tarifaires." Toulouse: Institut d'économie industrielle.

[13] CEER (Council of European Energy Regulators) (2018). Performance of European Retail Markets in 2017, CEER Monitoring Report C18-MRM-93-03.

[14] CRE (Commission de Régulation de l'Énergie) (2019). Observatoire des marchés de détail du 1er trimestre 2019, https://www.cre.fr/Documents/Publications/Observatoire-des-marches/Observatoiredes-marches-de-detail-du-1e-trimestre-2019

[15] CRE (Commission de Régulation de l'Énergie) (20182019). Wholesale Markets Observatory, 2018-Q4 to 2019-Q2. https://www.cre.fr/Documents/Publications/Observatoire-des-marches.

[16] Dasgupta, P. and E. Maskin (1986). "The Existence of Equilibrium in Discontinuous Economic Games I: Theory." The Review of Economic Studies, 53 (1): 1-26.

[17] Faiella, I. and L. Lavecchia (2018). "How Can You Fight It, If You Can’t Measure It?" mimeo.

[18] Finger, M. and D. Finon (2010). Network Industries and Markets : From Public Service Model to Universal Service Obligations. In Finger M. and R. Künneke (eds.), Handbook of Liberalised Infrastructure Sectors, London: Edward Elgar Publisher. 
[19] Florio, M. (2014). "Energy Reforms and Consumer Prices in the EU over Twenty Years." Economics of Energy \& Environmental Policy 3 (1): 37-51.

[20] Foellmi R. and J. Zweimüller (2004). "Inequality, Market Power, and Product Diversity." Economics Letters 82 (1): 139-145.

[21] Haber, H. (2011). "Regulating for Welfare: Varieties of Regulatory Welfare Regimes in the Israeli, British and Swedish Electricity Sectors." Law \& Policy 33 (1): 116-148.

[22] Hills, J. (2011). Fuel Poverty: The Problem and Its Measurement. Interim Report of the Fuel Poverty Review. Centre for Analysis of Social Exclusion, London School of Economics and Political Science.

[23] IEA (International Energy Agency) (2012). Energy Policies of IEA Countries: The Republic of Korea - 2012 Review, www.iea.org.

[24] Jeon, B. and S. Chung (2011), S. Korea to Add 100,000 Recipients to Basic Livelihood Security System Next Year. Maeil Broadcasting Network. accessed November 20th, 2019. https://www.mk.co.kr/news/english/view/2011/07/442550/.

[25] KEPCO: Korean Electric Power Company (2019). Corporate Website. Accessed November 20th, 2019. https://home.kepco.co.kr/kepco/EN/main.do.

[26] Kwon, S.-H. and J. Kim (2017). "Efficiency Versus Public Good: Electricity Privatization in South Korea." Asian Perspective 41 (2): 185-214.

[27] Léautier, T.-O. (2018). Imperfect Markets and Imperfect Regulation, MIT Press.

[28] Levinson, A. (2019). "Energy Efficiency Standards Are More Regressive than Energy Taxes: Theory and Evidence." Journal of the Association of the Environmental and Resource Economists 6 (S1): S7-S35.

[29] Majone, G. (1997). "From the Positive to the Regulatory State: Causes and Consequences of Changes in the Mode of Governance." Journal of Public Policy 17 (2): 139-167.

[30] MacKerron, G. (2012). "Foreword" [to the special issue on fuel poverty] Energy Policy 49: 1.

[31] Mas-Collel, A., M. D. Whinston and J. Green (1995). Microeconomic Theory. Oxford University Press. 
[32] MEIT (French Ministry for the Ecological and Inclusive Transition) (2018). Évaluation de l'expérimentation du chèque énergie. Accessed June 18th, 2019

https://www.ecologique-solidaire.gouv.fr/sites/default/files/Rapport evaluation cheque energie.pdf.

[33] MEIT (French Ministry for the Ecological and Inclusive Transition) (2019). Le chèqueénergie. https://www.chequeenergie.gouv.fr/beneficiaire/eligibilite, accessed June 18th, 2019.

[34] MOTIE (South Korean Ministry of Trade, Industry and Energy) (2014). Korea Energy Master Plan: Outlook and Policies to 2035. Accessed June 18th, 2019.

https://policy.asiapacificenergy.org/sites/default/files/2nd Energy Master Plan.pdf.

[35] Miniaci, R., Scarpa, C. and P. Valbonesi (2014). "Energy Affordability and the Benefits System in Italy." Energy Policy 75: 289-300.

[36] Moore, R. (2012). "Definitions of Fuel Poverty: Implications for Policy." Energy Policy 49: 19-26.

[37] ONPE (Observatoire national de la précarité énergétique) (2016). Les chiffres clés de la précarité énergétique. Accessed July 23rd, 2019.

http://onpe.org/nouvelles/les_chiffres_cles_de_la_precarite_energetique.

[38] Neuhoff, K., Back, S., Diekmann, J., Beznoska, M. and T. El-Laboudy (2013). "Distributional Effects of Energy Transition: Impacts of Renewable Electricity Support in Germany." Economics of Energy \& Environmental Policy 2 (1): 41-54.

[39] Poggi A. and M. Florio (2010). "Energy Deprivation Dynamics and Regulatory Reforms in Europe: Evidence from Household Panel Data." Energy Policy 38: 253-264.

[40] Poser, H., Altman, J., ab Egg, F., Granata, A. and R. Board (2014). Development and Integration of Renewable Energy: Lessons Learned from Germany. FinAdvice. Accessed August 20th, 2019.

http://catskillcitizens.org/learnmore/germany_lessonslearned_final_071014.pdf.

[41] Poudou, J.-C. and M. Roland (2017). "Equity Justifications for Universal Service Obligations." International Journal of Industrial Organization 52: 63-95.

[42] Reiss, P. C. and M. W. White (2005). "Household Electricity Demand, Revisited." The Review of Economic Studies 72 (3): 853-883. 
[43] Seade, J. (1980). "On the effects of entry." Econometrica 48 (2): 479-489.

[44] Stoft, S. (2002). Power System Economics. Wiley Interscience.

[45] H. Thomson, Bouzarovski, S. and C. Snell (2017). "Rethinking the Measurement of Energy Poverty in Europe: A Critical Analysis of Indicators and Data." Indoor and Built Environment 26 (7): 879-901.

[46] Yi, J. and C. P. Park, Electricity Regulation in South Korea, Lexology. Accessed November 20th, 2019.

https://www.lexology.com/library/detail.aspx?g=4a7f6594-b6b4-4249-a928a0e02ed683e5.

[47] Yoo, E. and J. Seo (2018). "Urban-Rural Energy Inequity in Korea and Policy Solutions." Foundation for Renewable Energy $\&$ Environment (FREE) Working Paper.

[48] Yun, T and K. Park (2017). Measuring Energy Poverty and Analyzing Energy Consumption Characteristics. Korea Energy Economics Institute, Policy Paper 17-01. 


\section{Appendix}

\section{Proof of Lemma 1}

We have:

$$
\hat{\Omega}(p)=\frac{\hat{Q}^{\prime \prime}(p)}{\hat{Q}^{\prime}(p)} p=\frac{\int_{\Theta} p \hat{q}_{p}^{\prime \prime} d F}{\int_{\Theta} \hat{q}_{p}^{\prime} d F}=\frac{\int_{\Theta} \omega(p, \theta) \hat{q}_{p}^{\prime} d F}{\int_{\Theta} \hat{q}_{p}^{\prime} d F} \geq-2
$$

since $\omega(p, \theta) \geq-2, \forall \theta$ by Assumption $1 \mathrm{c})$.

\section{Proof of Lemma 2}

a) Differentiating $s$ in (6) with respect to $\theta$, we obtain:

$$
s_{\theta}^{\prime}(p, t, \theta)=\left\{\begin{array}{cr}
-\frac{t}{(t+\theta)^{2}}<0 & \theta<\theta_{t}(p, t) \\
\frac{s(p, 0, \theta+t)}{\theta+t}(\varepsilon(p, \theta+t)-1)<0 & \text { if } r>\theta_{t}(p, t)
\end{array}\right.
$$

where $s_{\theta}^{\prime}$ is not defined at $\theta_{t}(p, t)$ and where the inequality for the case $\theta>\theta_{t}(p, t)$ follows Assumption 1 a).

b) Differentiation with respect to $p$ gives:

$$
s_{p}^{\prime}(p, t, \theta)=\left\{\begin{array}{cr}
0 & \text { if } \begin{array}{c}
\theta<\theta_{t}(p, t) \\
\frac{s(p, 0, \theta+t)}{p}(1-\eta(p, \theta+t))
\end{array} \quad \theta>\theta_{t}(p, t)
\end{array}\right.
$$

where $s_{p}^{\prime}$ is not defined at $\theta_{t}(p, t)$. For $\theta>\theta_{t}(p, t)$, we see directly that $s_{p}^{\prime} \gtrless 1$ as $\eta \lessgtr 1$.

c) Differentiation with respect to $t$ gives:

$$
s_{t}^{\prime}(p, t, \theta)=\left\{\begin{array}{cr}
\frac{\theta}{(t+\theta)^{2}}>0 \\
s_{\theta}^{\prime}(p, t, \theta)<0
\end{array} \quad \text { if } \begin{array}{r}
\theta<\theta_{t}(p, t) \\
\theta>\theta_{t}(p, t)
\end{array}\right.
$$

\section{Proof of Lemma 3}

Since, for any $\theta \in \Theta_{v}$, the elasticity of the demand slope is $\omega(p, \theta)=-2$, we obtain:

$$
\begin{aligned}
\Omega(p, \mathbf{t})= & \frac{\hat{Q}_{p}^{\prime \prime}(p, \mathbf{t})}{\hat{Q}_{p}^{\prime}(p, \mathbf{t})} p=\frac{\int_{\Theta_{f}} \omega(p, \theta) \hat{q}_{p}^{\prime} d F d F+2 \int_{\Theta_{v}} \frac{t}{p^{2}} d F}{\int_{\Theta_{f}} \hat{q}_{p}^{\prime} d F-\int_{\Theta_{v}} \frac{t}{p^{2}} d F} \\
& \geq \frac{-2\left(\int_{\Theta_{f}} \hat{q}_{p}^{\prime} d F d F-\int_{\Theta_{v}} \frac{t}{p^{2}} d F\right)}{\int_{\Theta_{f}} \hat{q}_{p}^{\prime} d F-\int_{\Theta_{v}} \frac{t}{p^{2}} d F}=-2
\end{aligned}
$$




\section{Proof of Lemma 4}

a) In order to obtain $\frac{\partial E}{\partial t(\theta)}$, we consider that the voucher $t$ is varying at a mass point $\theta$ only. As a result, we adopt the following conventions for the variations of aggregate expressions:

$$
\frac{\partial Q}{\partial t(\theta)}=\frac{\partial q(p, t(\theta), \theta)}{\partial t(\theta)}
$$

and

$$
\begin{aligned}
\frac{\partial\left(\int_{\underline{\theta}}^{\bar{\theta}} q(p, t(\tau), \tau) \eta(p, t(\tau), \tau) d F\right)}{\partial t(\theta)} & =\frac{\partial(q(p, t(\theta), \theta) \eta(p, t(\theta), \theta) d F)}{\partial t(\theta)} \\
& =q_{t}^{\prime} \eta+q \eta_{t}^{\prime}
\end{aligned}
$$

So we have:

$$
\begin{aligned}
\frac{\partial E}{\partial t(\theta)} & =\frac{\frac{\partial\left(\int_{\underline{\theta}}^{\bar{\theta}} q(p, t(\tau), \tau) \eta(p, t(\tau), \tau) d F\right)}{\partial t(\theta)} Q-\left(\int_{\underline{\theta}}^{\bar{\theta}} q(p, t(\tau), \tau) \eta(p, t(\tau), \tau) d F\right) \frac{\partial Q}{\partial t(\theta)}}{Q^{2}} \\
& =\frac{\left(q_{t}^{\prime} \eta+q \eta_{t}^{\prime}\right) Q-Q E q_{t}^{\prime}}{Q^{2}} \\
& =\frac{(\eta-E) q_{t}^{\prime}+q \eta_{t}^{\prime}}{Q}
\end{aligned}
$$

b) For interior points of $\Theta_{v}$, the elasticity is not modified by a change of $t(\theta)$ since the individual elasticities remain equal to 1 and $\frac{\partial Q_{\Theta_{f}}}{\partial t(\theta)}=\frac{\partial Q}{\partial t(\theta)}$.

c) At a frontier point $\theta$ of $\Theta_{f}$ and $\Theta_{v}$, we have:

$$
\frac{\partial E(p, \mathbf{t})}{\partial t(\theta)}=\frac{\partial\left(\frac{Q_{\Theta_{f}}}{Q}\right)}{\partial \theta}(\eta-1) \lessgtr 0 \text { as } \eta \gtrless 1
$$

where we use the fact that $\frac{\partial\left(\frac{Q_{\Theta_{f}}}{Q}\right)}{\partial \theta}<0$, since increasing $t(\theta)$ makes consumers having income $\theta$ move from $\Theta_{f}$ to $\Theta_{v}$.

Proof of Lemma 5. If non zero, the optimal voucher obeys:

$$
t: \frac{p \hat{q}(p, \theta+t)}{\theta+t}=\alpha
$$

By definition of $\theta_{\alpha}(p)$, we also have:

$$
\frac{p \hat{q}\left(p, \theta_{\alpha}(p)\right)}{\theta_{\alpha}}=\alpha
$$


But, as $s_{\theta}^{\prime}(p, t, \theta)<0$, consumers with $\theta \leq \theta_{\alpha}(p)$ will have an energy expenditure share that exceeds $\alpha$, so that vouchers must be allocated to make these consumers attain an income level equal to $\theta_{\alpha}(p)$ :

$$
t^{*}(\theta, p)=\theta_{\alpha}(p)-\theta
$$

\section{Proof of Proposition 1}

For a given price $p$, we get:

$$
\begin{aligned}
E^{n}\left(p_{n}, \mathbf{t}_{n}\right) & =\frac{Q_{\Theta_{t}}}{Q} \eta\left(p_{n}, \theta_{\alpha}\left(p_{n}\right)\right)+\frac{Q_{\Theta_{0}}}{Q} E_{\Theta_{0}}\left(p_{n}, 0\right) \\
& =\frac{1}{Q} \int_{\Theta_{t}} \hat{q}\left(p_{n}, \theta_{a}\left(p_{n}\right)\right) \eta\left(p_{n}, \theta_{\alpha}\left(p_{n}\right)\right) d F+\frac{Q_{\Theta_{0}}}{Q} E_{\Theta_{0}}\left(p_{n}, 0\right) \\
& >\frac{1}{Q} \int_{\Theta_{t}} \hat{q}\left(p_{n}, \theta\right) \eta\left(p_{n}, \theta\right) d F+\frac{Q_{\Theta_{0}}}{Q} E_{\Theta_{0}}\left(p_{n}, 0\right) \\
& =E_{0}\left(p_{n}\right)
\end{aligned}
$$

where the inequality comes from the facts that $\hat{q}\left(p_{n}, \theta_{a}\left(p_{n}\right)\right)>\hat{q}\left(p_{n}, t(\theta)\right)$ and $\eta\left(p_{n}, \theta_{\alpha}\left(p_{n}\right)\right)>$ $\eta\left(p_{n}, \theta\right)$. Then, at $p_{n}$, we have $\mathcal{L}\left(p_{n}\right)=\frac{1}{E^{n}\left(p_{n}, \mathbf{t}_{n}\right)}<\frac{1}{E_{0}\left(p_{n}\right)}$ so that $p_{0}>p_{n}$.

\section{Proof of Lemma 6}

The demand function when firms move first is:

$$
Q\left(p, \mathbf{t}^{*}(\theta, p)\right)=\int_{\underline{\theta}}^{\theta_{\alpha}(p)} \frac{\alpha \theta_{\alpha}(p)}{p} d F+\int_{\theta_{\alpha}(p)}^{\bar{\theta}} \hat{q}(p, \theta) d F
$$

We then have:

$$
\begin{aligned}
\frac{d Q}{d p} & =\int_{\underline{\theta}}^{\theta_{\alpha}(p)} \frac{\alpha\left(p \theta_{\alpha}^{\prime}(p)-\theta_{\alpha}(p)\right)}{p^{2}} d F+\int_{\theta_{\alpha}(p)}^{\bar{\theta}} \hat{q}_{p}^{\prime} d F \\
& =\int_{\underline{\theta}}^{\theta_{\alpha}(p)} \frac{q_{\alpha}}{p}\left(\frac{\varepsilon_{s}-\eta_{s}}{1-\varepsilon_{s}}\right) d F+\int_{\theta_{\alpha}(p)}^{\bar{\theta}} \hat{q}_{p}^{\prime} d F
\end{aligned}
$$

with $q_{\alpha}=\frac{\alpha \theta_{\alpha}(p)}{p}$ and where for all $p$,

$$
\eta_{s}=\eta\left(p, \theta+t^{*}(\theta, p)\right)=\eta\left(p, \theta_{\alpha}(p)\right)
$$

We thus obtain for all $p$ :

$$
E^{s}\left(p, \mathbf{t}^{*}(\theta ; p)\right)=\frac{Q_{\Theta_{t}}}{Q}\left(\frac{\eta_{s}-\varepsilon_{s}}{1-\varepsilon_{s}}\right)+\frac{Q_{\Theta_{0}}}{Q} E_{\Theta_{0}}(p, 0)
$$


With $\varepsilon_{s}<1$ and $\eta_{s}<1$ for all $\theta \in \Theta_{t}$, we have $\frac{\eta_{s}-\varepsilon_{s}}{1-\varepsilon_{s}}<\eta_{s}{ }^{48}$ For a given price $p$ and voucher policy $\mathbf{t}$, we thus obtain:

$$
E^{s}\left(p, \mathbf{t}^{*}(\theta ; p)\right)<E^{n}(p, \mathbf{t})
$$

\section{Proof of Proposition 2}

For a fixed price $p$, we have $E^{s}\left(p, \mathbf{t}^{*}(\theta ; p)\right)<E^{n}(p, \mathbf{t})$, so that:

$$
\mathcal{L}\left(p_{r}\right)=\frac{1}{E^{s}\left(p_{s}, \mathbf{t}^{*}\left(\theta ; p_{s}\right)\right)}>\frac{1}{n E^{n}\left(p_{s}, \mathbf{t}\right)}
$$

Since $\frac{\partial E^{n}}{\partial p}>0$ and $\mathcal{L}^{\prime}(p)>0$, and $p_{n}$ is such that $\mathcal{L}\left(p_{s}\right)=\frac{1}{n E^{n}\left(p_{n}, \mathbf{t}\right)}$, we must have $p_{n}<p_{s}$.

\section{Proof of Corollary 1}

We have $p_{n}<p_{0}$ from Proposition 1 and $p_{n}<p_{s}$ from Proposition 2, so that $p_{s}$ can either be greater than or lesser than $p_{0}$.

Proof of Proposition 3. This comes directly from the fact that $\mathbf{t}=\mathbf{t}_{n}$ is feasible when the regulator moves first.

\section{Proof of Proposition 4}

When $t^{\prime}(\theta) \leq 0$, the regulator chooses $t\left(\theta, p_{v}(\mathbf{t})\right)=\max \left\{\theta_{\alpha}\left(p_{v}(\mathbf{t})\right)-\theta, 0\right\}$, i.e. it chooses $\mathbf{t}$ that minimizes $\theta_{\alpha}\left(p_{v}(\mathbf{t})\right)$. By definition, $\theta_{\alpha}\left(p_{v}(\mathbf{t})\right)$ is such that $s\left(p_{v}(\mathbf{t}), 0, \theta_{\alpha}\left(p_{v}(\mathbf{t})\right)\right)=\alpha=$ $s\left(p_{n}, 0, \theta_{\alpha}\left(p_{n}\right)\right)$. Trying to deviate from the Nash equilibrium, we must induce a price such that:

$$
s_{p}^{\prime}+s_{\theta}^{\prime} \frac{d \theta_{\alpha}}{d p}=0 \Rightarrow \frac{d \theta_{\alpha}}{d p}=-\frac{s_{p}^{\prime}}{s_{\theta}^{\prime}}>0
$$

so that a decrease in vouchers must induce a decrease in price. But, starting at price $p_{n}$, a decrease of vouchers decreases the elasticity of all consumers below $\theta_{\alpha}\left(p_{n}\right)$, so that the aggregate elasticity is reduced. Then firms react with an increase in price rather than a decrease. As a result, the regulator cannot escape the Nash equilibrium.

\footnotetext{
${ }^{48}$ If $\eta_{s}<\varepsilon_{s}<1$, an increase in price increases the demand of eligible consumers because of the voucher adjustment. This can be an equilibrium if a further increase in price would bring a lesser increase in demand from eligible consumers than the loss from non-eligible consumers.
} 
Figures

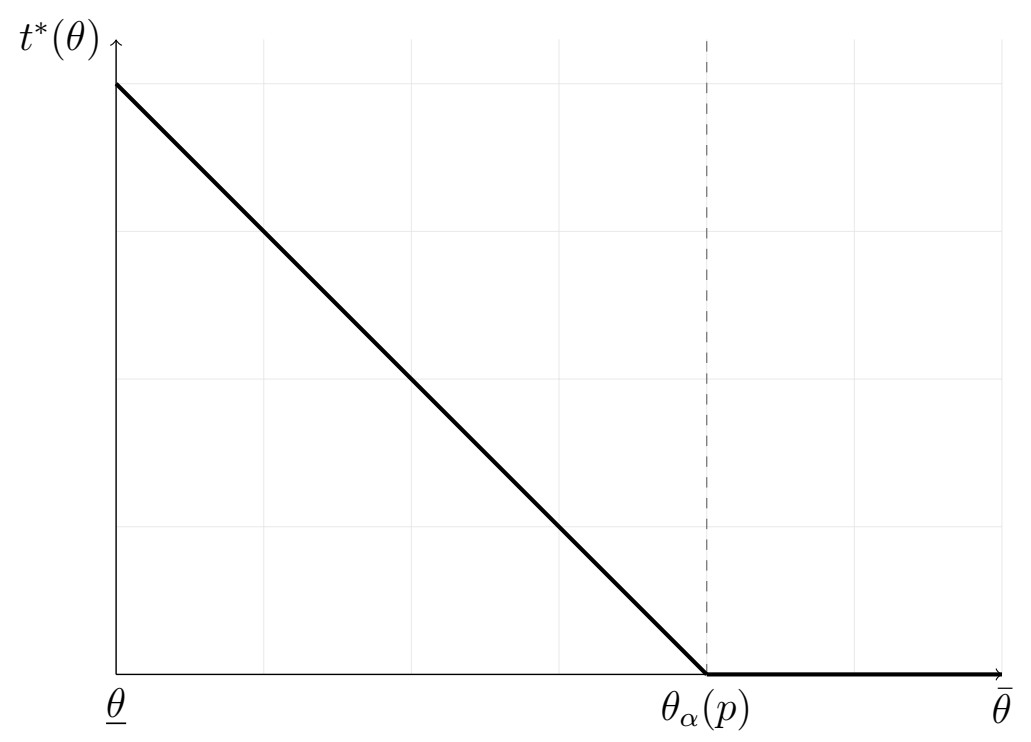

Figure 1: Voucher policy 


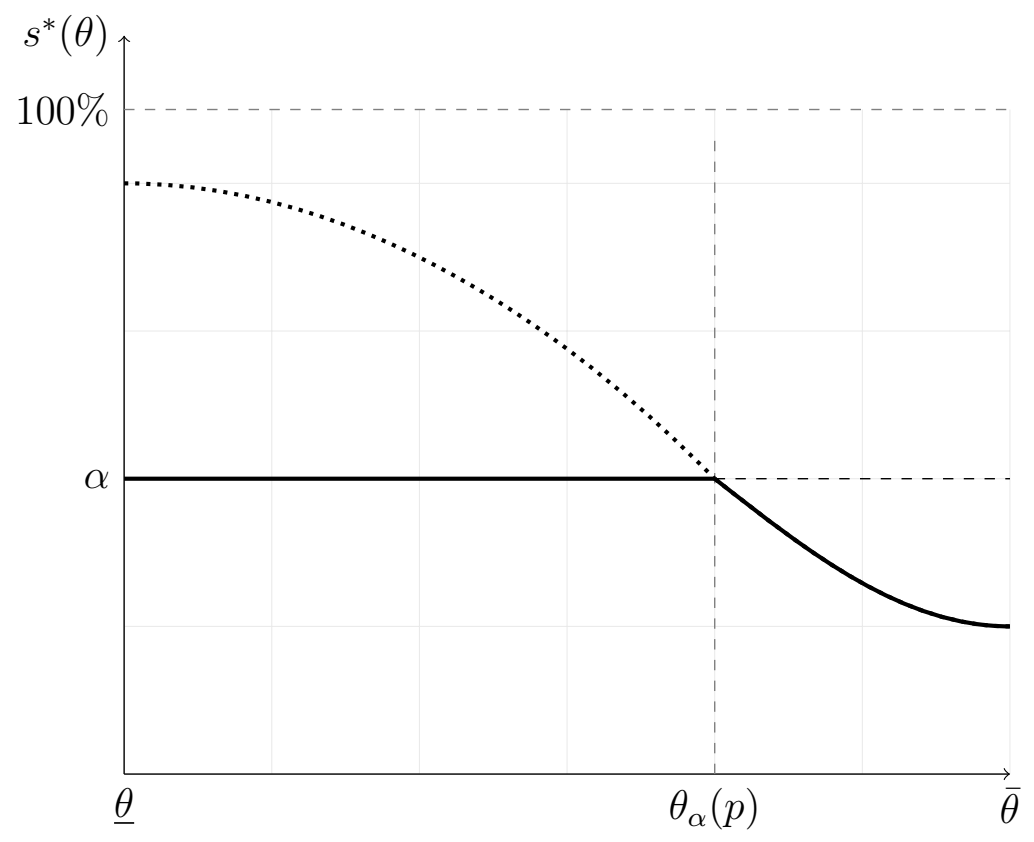

Figure 2: Energy net budget shares

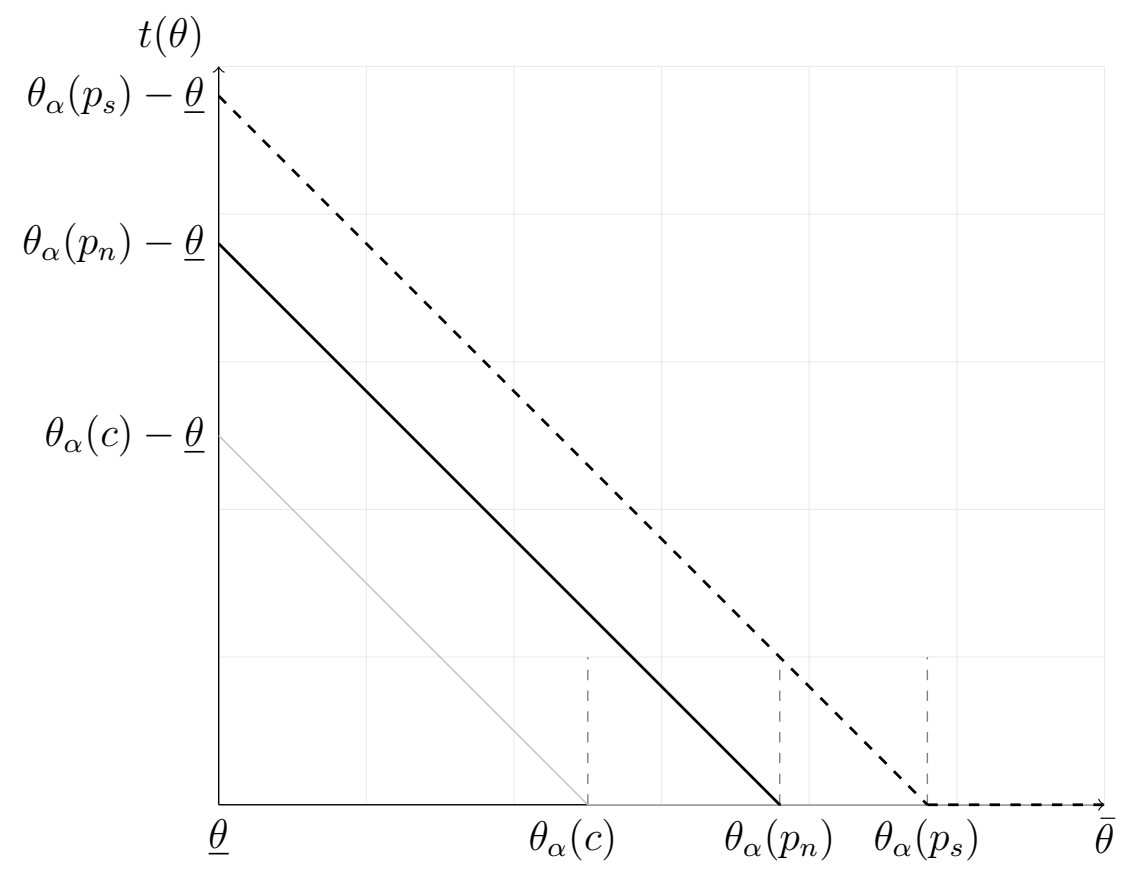

Figure 3: Voucher schemes: Nash (plain) \& Firm first (dashed) 


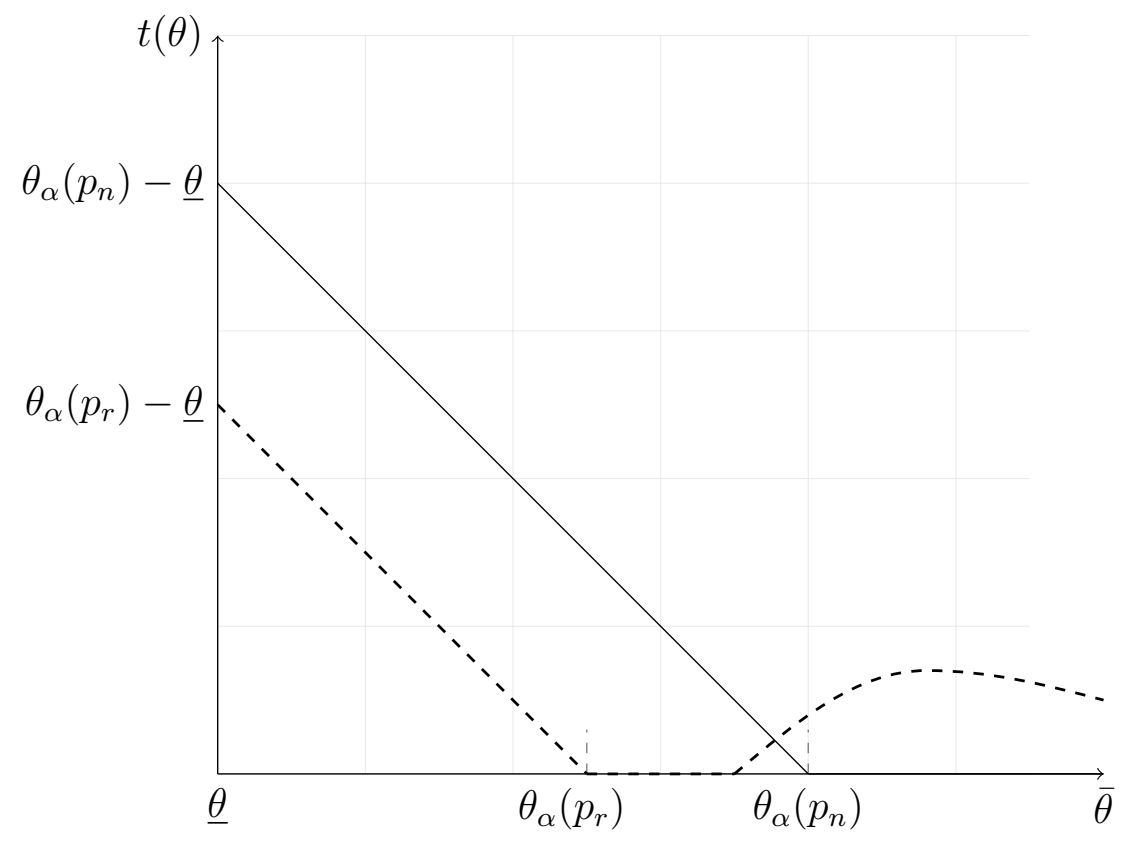

Figure 4: Voucher schemes: Nash (plain) \& Regulator first (dashed) 